Applied Energy

Volume 238, 15 March 2019, Pages 1237-1249

\title{
Heat Removal Efficiency of Stratum Ventilation for Air-side Modulation
}

\author{
Sheng Zhang ${ }^{1}$, Yong Cheng ${ }^{2,3}$, Majeed Olaide Oladokun ${ }^{1}$, Chao Huan ${ }^{4}$, Zhang $\operatorname{Lin}^{5 *}$ \\ $\left({ }^{1}\right.$ Department of Architecture and Civil Engineering, City University of Hong Kong, \\ Hong Kong, China \\ ${ }^{2}$ Joint International Research Laboratory of Green Buildings and Built Environments, \\ Ministry of Education, Chongqing University, Chongqing, China \\ ${ }^{3}$ Key Laboratory of Three Gorges Reservoir Region's Eco-Environment, Ministry of \\ Education, Chongqing University, Chongqing, China \\ ${ }^{4}$ School of Energy and Resource, Xi'an University of Science and Technology, Xi'an, \\ China
}

${ }^{5}$ Division of Building Science and Technology, City University of Hong Kong, Hong Kong, China

*Corresponding author. Tel.: +852 34429805; fax: +852 34429716; E-mail:

bsjzl@cityu.edu.hk)

\begin{abstract}
Stratum ventilation has significant thermal non-uniformity between the occupied and upper zones. Although the non-uniformity benefits indoor air quality and energy efficiency, it increases complexities and difficulties in the air-side modulation. In this study, a heat removal efficiency (HRE) model is first established and validated, and then used for the air-side modulation. The HRE model proposed is a function of supply air temperature, supply airflow rate and cooling load. The HRE model proposed has been proven to be applicable to stratum ventilation and displacement ventilation for different room geometries and air terminal configurations, with errors generally within $\pm 5 \%$ and a mean absolute error less than $4 \%$ for thirty-three experimental cases and five simulated cases. Investigations into the air-side modulation with the proposed HRE model reveal that for both the typical stratum-ventilated classroom and office, the variable-air-volume system can serve a wider range of cooling load than the constant-air-volume system. The assumption of a constant HRE used in the conventional method could lead to errors in the room temperature prediction up to $\pm 1.3^{\circ} \mathrm{C}$, thus the proposed $\mathrm{HRE}$ model is important to the
\end{abstract}


Applied Energy

Volume 238, 15 March 2019, Pages 1237-1249

air-side modulation for thermal comfort. An air-side modulation method is proposed based on the HRE model to maximize the HRE for improving energy efficiency while maintaining thermal comfort. Results show that the HRE model based air-side modulation can improve the energy efficiency of stratum ventilation up to $67.3 \%$. The HRE model based air-side modulation is also promising for displacement ventilation.

Keywords: Heat removal efficiency; Experiment and modeling; Stratum ventilation; Displacement ventilation; Non-uniformity; Air-side modulation

\section{Nomenclature}

\begin{tabular}{|c|c|}
\hline$a, \mathrm{~b}, \mathrm{c}$ & constant coefficients in HRE model \\
\hline$c_{p}$ & $\begin{array}{l}\text { specific heat capacity of air } \\
\left(\mathrm{kJ} /\left(\mathrm{kg} \cdot{ }^{\circ} \mathrm{C}\right)\right)\end{array}$ \\
\hline$\rho$ & air density $\left(\mathrm{kg} / \mathrm{m}^{3}\right)$ \\
\hline$Q_{\mathrm{cl}}$ & cooling load $(\mathrm{kW})$ \\
\hline$T_{\mathrm{e}}$ & exit air temperature $\left({ }^{0} \mathrm{C}\right)$ \\
\hline$T_{\mathrm{r}}$ & room temperature $\left({ }^{0} \mathrm{C}\right)$ \\
\hline$T_{\mathrm{s}}$ & supply air temperature $\left({ }^{0} \mathrm{C}\right)$ \\
\hline$V_{\mathrm{s}}$ & supply airflow rate $\left(\mathrm{m}^{3} / \mathrm{s}\right)$ \\
\hline
\end{tabular}

\section{Abbreviations}

$\mathrm{ACH}$ air changes per hour

CAV constant-air-volume

HRE heat removal efficiency

PMV Predicted Mean Vote

SV stratum ventilation

VAV variable-air-volume

\section{Introduction}

Improving energy efficiency of HVAC is a critical mission for low and zero energy buildings [1, 2]. HVAC provides thermal comfort, but accounts for the largest amount of building energy consumption, e.g., around 50\%, 35\% and 40\% in commercial buildings in the US, UK and Spain respectively [3]. Reducing energy consumption of ventilation system plays a vital role in improving the energy efficiency of HVAC systems [4-7]. The conventional air distribution, mixing ventilation, creates an acceptable thermal environment with a penalty of high energy consumption [8]. Mixing ventilation conditions the space uniformly, leading to wasteful energy use in conditioning the upper zone (without occupants) [9]. Collective air distributions (e.g., displacement ventilation and stratum ventilation) focus on the occupied zone, with a non-uniform thermal environment between the occupied zone and upper unoccupied 
Applied Energy

Volume 238, 15 March 2019, Pages 1237-1249

zone [10]. Because of the non-uniformity, part of the energy used for the unoccupied upper zone is saved [11].

Stratum ventilation delivers conditioned air horizontally to the breathing zone, so that air in the breathing zone is young $[12,13]$. Stratum ventilation generates a sandwich temperature and velocity profiles, with the lowest temperature and highest velocity at the head level $[14,15]$, which cools the body more effectively for thermal comfort [16, 17]. A series of experimental, numerical and human subjective studies have shown that stratum ventilation can robustly achieve satisfactory thermal comfort with symmetrically/asymmetrically distributed heat gains [18-22], and provide quality inhaled air $[12,23,24]$. Annual energy performance simulations found that stratum ventilation saved energy use by at least $44 \%$ as compared with mixing ventilation [25]. Stratum ventilation is applicable to small-to-medium-sized rooms and has been studied for offices, classrooms and retail shops [25].

However, the air-side modulation of the room temperature with stratum ventilation lacks investigations. The non-uniform thermal environment makes it challenging to predict the room temperature [26, 27]. Without accurate prediction of the room temperature, thermal comfort and energy efficiency might not be assured during building operation [28, 29]. Huan et al. [26] developed a multiple-node model for predicting the room temperature of stratum ventilation. This method has the application potential for the annual energy performance evaluation with building energy simulation tools when the cooling load of the non-uniform thermal environment is carefully estimated [30]. However, regarding the real building operation, it requires additional sensors for the wall temperatures/heat fluxes besides the sensors used in common practice for the supply airflow rate, supply air temperature and exit air temperature [26]. The additional sensors increase the cost and control complexities in practice $[31,32]$.

The air-side modulation based on the heat removal efficiency (HRE) is a promising solution to the collective air distributions with a non-uniform thermal environment [25, 33-37]. With the HRE, supply condition (i.e., supply airflow rate and supply air temperature) and exit air temperature, the room temperature can be predicted and appropriately modulated for thermal comfort $[35,37]$. Since the supply condition and 
Applied Energy

Volume 238, 15 March 2019, Pages 1237-1249

exit air temperature can be conveniently obtained with sensors installed under common practice [38], the aforementioned additional sensor cost and control complexities can be avoided by adopting the HRE based air-side modulation. Besides, the HRE, as a ventilation effectiveness index, is also widely used to reflect the efficiency of energy use $[10,39,40]$. Improving the HRE during the air-side modulation can improve the energy efficiency of the ventilation system [9, 41-43].

However, it remains as a challenge to estimate the HRE accurately for the air-side modulation in practice. The HRE highly depends on the supply condition and cooling load. Chen et al. [44] experimentally found that, for displacement ventilation, a higher supply airflow rate helped to improve the HRE. Huan et al. [21] experimentally revealed that the HRE of stratum ventilation increased with the increasing cooling load. Since the supply condition and cooling load can vary largely in practice, the HRE can also vary significantly, e.g., by $13 \%$ from around 1.28 to 1.45 reported by Huan et al. [21] for stratum ventilation. Although HRE can be estimated via experiments and CFD simulations, it is costly to produce comprehensive results of HRE with the largely varying supply condition and cooling load in practice.

Therefore, this study develops an HRE model as a function of the supply condition and cooling load. Following this section (Section 1), the HRE model is determined and validated with experimental data from two typical stratum-ventilated rooms (i.e., a medium-sized classroom with mid-level exits and a small-sized office with ceiling-level exit) (Sections 2 and 3). The applicability of the proposed HRE model is further analyzed by extrapolating the HRE model to wider ranges of the supply condition and cooling load beyond the model determination, and by extending the HRE model to two displacement ventilation systems (Section 4). Lastly, the application and effectiveness of the HRE model proposed for the air-side modulation are demonstrated to improve energy efficiency while maintaining thermal comfort (Sections 5 and 6). The HRE model based air-side modulation can be used for both the design and control of stratum ventilation and is also promising for the design and control of displacement ventilation. 


\section{Applied Energy}

Volume 238, 15 March 2019, Pages 1237-1249

\section{Methodology}

\subsection{Overview of methodology}

HRE is defined as the ratio of the temperature difference between the exit air and supply air to the temperature difference between the room air and supply air (Equation 1). With the HRE, supply airflow rate, and supply and exit air temperatures, Equations 1 and 2 can be solved to obtain the room temperature for air-side modulation. This study mainly includes three parts (Figure 1). Firstly, The HRE model proposed (Equation 3) is determined and validated with experiments for two typical stratum-ventilated rooms. The stratum-ventilated classroom is medium-sized with mid-level exits, and the stratum-ventilated office is small-sized with ceiling-level exit. Although the room geometries and air terminal configurations can significantly affect the HRE $[39,41]$, the same HRE model form is shared by the two stratum-ventilated rooms (Equation 3). The HRE model proposed is an empirical model, which is in a function of the supply condition and cooling load with only three constant coefficients (Equation 3). The three constant coefficients are determined by experimental data using multiple regression. Actually, in the field of indoor built environment, there are many widely used empirical models, e.g., the PMV-PPD model $[45,46]$, the adaptive thermal comfort model [47], the model of the maximum velocity decay of impinging jet ventilation [48], the velocity decay model of air curtain ventilation [49], and the interface height model of underfloor air distribution [50]. Due to the complexity of indoor air distribution, these empirical models lack mathematical derivations [51-54]. Although these empirical models are obtained using the iterative improvement approach based on the observations of extensive experiments/simulations without mathematical derivations, they are powerful for the design and control of the indoor built environment. The HRE model (Equation 3) is also developed using an iterative improvement approach based on the observations of extensive experimental results. Secondly, the applicability of the HRE model is further proven by extrapolating it to the supply condition and cooling load broader than the experiments used for the HRE 


\section{Applied Energy}

Volume 238, 15 March 2019, Pages 1237-1249

model determination. The applicability of the HRE model is also tested with displacement ventilation using the data reported by Chen et al. [44].

$$
\begin{aligned}
& H R E=\frac{T_{\mathrm{e}}-T_{\mathrm{s}}}{T_{\mathrm{r}}-T_{\mathrm{s}}} \\
& Q_{\mathrm{cl}}=\rho c_{\mathrm{p}} V_{\mathrm{s}}\left(T_{\mathrm{e}}-T_{\mathrm{s}}\right) \\
& \frac{1}{H R E}=\frac{V_{\mathrm{s}}\left(a+b T_{\mathrm{s}}\right)}{Q_{\mathrm{cl}}}+c
\end{aligned}
$$

where $a, b$ and $c$ are the three constant coefficients of the HRE model; $c_{\mathrm{p}}$ is the specific heat capacity of air $\left(\mathrm{kJ} /\left(\mathrm{kg} \cdot{ }^{0} \mathrm{C}\right)\right) ; H R E$ is the heat removal efficiency; $\rho$ is the air density $\left(\mathrm{kg} / \mathrm{m}^{3}\right) ; Q_{\mathrm{cl}}$ is the cooling load $(\mathrm{kW}) ; T_{\mathrm{e}}, T_{\mathrm{r}}$ and $T_{\mathrm{s}}$ are the temperatures of exit air, room air in the occupied zone and supply air respectively $\left({ }^{0} \mathrm{C}\right) ; V_{\mathrm{s}}$ is the supply airflow rate $\left(\mathrm{m}^{3} / \mathrm{s}\right)$.

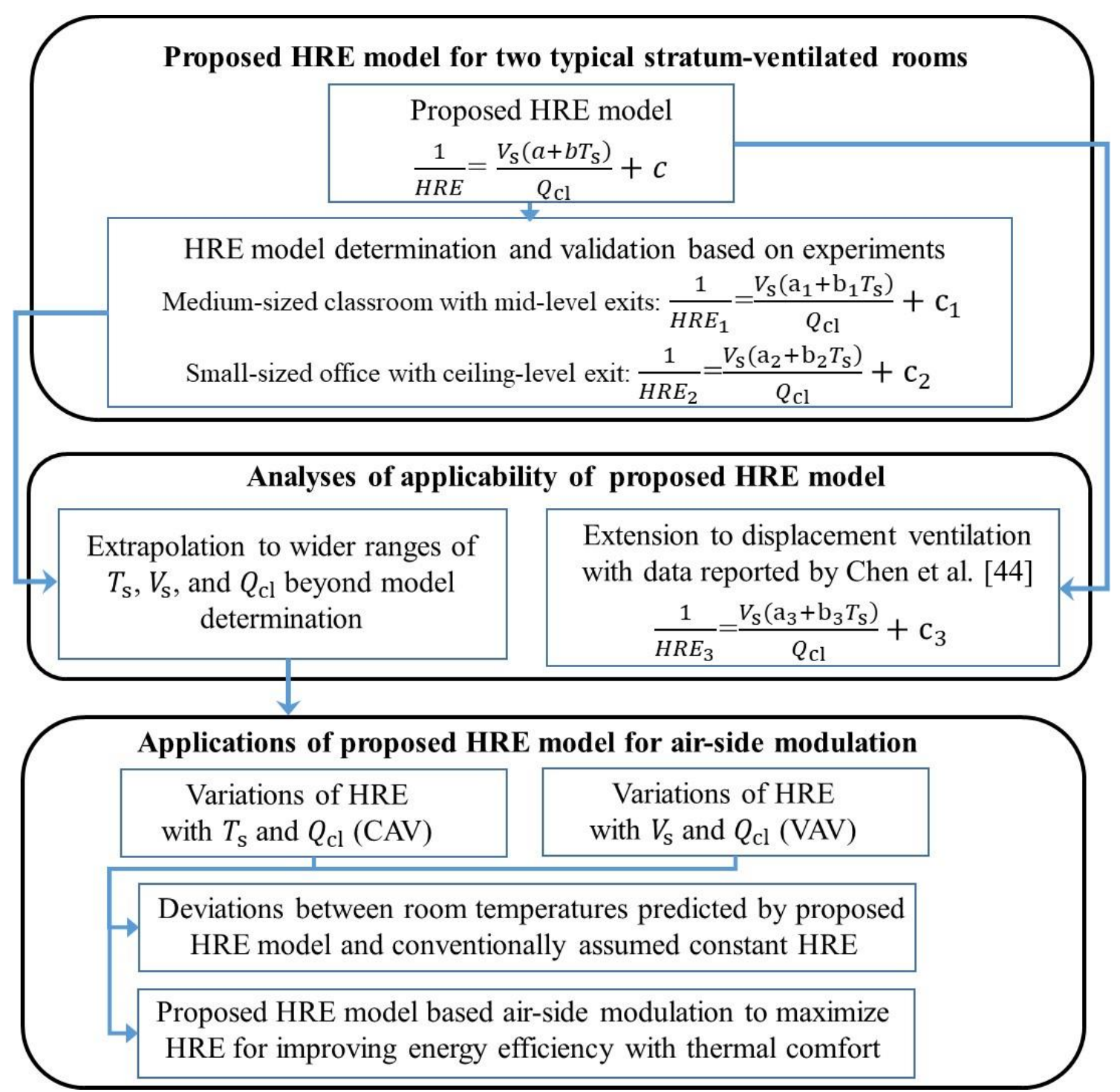


Applied Energy

Volume 238, 15 March 2019, Pages 1237-1249

Note: $T_{s}, V_{s}$ and $Q_{c l}$ denote the supply air temperature, supply airflow rate and cooling load respectively; $a, b, c$ are three constant coefficients of the heat removal efficiency (HRE) model; CAV and VAV denote the constant-air-volume system and variable-air-volume system respectively.

Fig.1. Overview of methodology.

Thirdly, the proposed HRE model is demonstrated to be used for the air-side modulation. Both the constant-air-volume and variable-air-volume systems are taken into consideration for the two typical stratum-ventilated rooms. Conventionally, since no HRE model is available, a constant HRE is simplifiedly assumed for the air-side modulation [25, 35, 37, 55]. The air-side modulation based on a constant HRE outperforms the network/multi-zone models which ignore the non-uniformity of the thermal environment [10]. The extent to which the HRE value varies with the supply condition and cooling load is investigated with the validated HRE model. A large variation of the HRE implies that the conventionally assumed constant HRE is inadequate for the air-side modulation. The room temperatures predicted by the proposed HRE model and by the conventionally assumed constant HRE are also compared. The larger deviation between the two room temperature predictions, the more deficient the conventionally assumed constant HRE for the air-side modulation for thermal comfort. Due to the deficiency of the conventionally assumed constant HRE, the proposed HRE model is essential for the air-side modulation for thermal comfort. It is noted that the room temperature predicted by the proposed HRE model is considered as credible, which will be validated by the experiments. Moreover, an air-side modulation method based on the HRE model is proposed to maximize the HRE for improving the energy efficiency while maintaining thermal comfort.

\subsection{Experiments in medium-sized stratum-ventilated classroom with mid-level exits}

The stratum-ventilated classroom with mid-level exits is located in City University of Hong Kong (Figure 2). The classroom is medium-sized with dimensions of $8.8 \mathrm{~m}$ (length) $\times 6.1 \mathrm{~m}$ (width) $\times 2.4 \mathrm{~m}$ (height). The air horizontally enters the breathing zone from four supply diffusers S1-S4 on the front wall at the height of $1.3 \mathrm{~m}$, and then exits through four exit louvers E1-E4 on the rear wall at the same height. Perforation diffusers and double deflection grilles are used as the supply and exit air 
Applied Energy

Volume 238, 15 March 2019, Pages 1237-1249

terminals respectively [19]. Two rows with eight seats in each are arranged for occupants (numbered 1 to 16). Sixteen thermal manikins represent students with dimensions around $400 \mathrm{~mm}$ (length) $\times 250 \mathrm{~mm}$ (width) $\times 1200 \mathrm{~mm}$ (height). Each thermal manikin is heated by a $100 \mathrm{~W}$ light bulb $[13,56]$. Similar to Cheng et al. [18, 19], the heat generated by the radiators is adjusted to control the cooling load. The radiators are separated from the occupied zone by boards. Thus, the change in cooling load can be regarded to be caused by the outdoor weather condition [18, 19]. Eight sampling points at the height of $1.1 \mathrm{~m}$ (i.e., M1-M8) are evenly arranged for the room temperature measurements. Measurements at the height of $1.1 \mathrm{~m}$ (for seated occupants) are adequate for thermal comfort evaluation of stratum ventilation [18, 37]. SWEMA omnidirectional hot-wire anemometers with data logger are used with a measuring accuracy of $\pm 0.2^{\circ} \mathrm{C}$ between $10^{\circ} \mathrm{C}$ and $40^{\circ} \mathrm{C}$. Temperatures of the supply and exit air are measured at the air terminals. The supply airflow rate is measured at the supply diffusers by ALNOR balometer capture hood EBT731, with a measuring accuracy of $\pm 3 \%$ of reading between $0.012 \mathrm{~m}^{3} / \mathrm{s}$ and $1.181 \mathrm{~m}^{3} / \mathrm{s}$.

Fifteen cases (numbered 1 to 15 in Table 1) are designed for the aforementioned measurements, covering wide ranges of the supply air temperature $\left(19.81^{\circ} \mathrm{C}\right.$ to $\left.29.44^{0} \mathrm{C}\right)$, supply airflow rate $\left(0.201 \mathrm{~m}^{3} / \mathrm{s}\right.$ to $\left.0.373 \mathrm{~m}^{3} / \mathrm{s}\right)$, cooling load $(0.52 \mathrm{~kW}$ to $1.98 \mathrm{~kW})$, exit air temperature $\left(23.79^{\circ} \mathrm{C}\right.$ to $\left.31.95^{\circ} \mathrm{C}\right)$ and room temperature $\left(23.23^{\circ} \mathrm{C}\right.$ to $31.15^{\circ} \mathrm{C}$ ). The supply air temperature and supply airflow rate are the mean and sum of the measurements at the four supply diffusers S1-S4 respectively. The exit air temperature is the mean of the measurements at the four exit louvers E1-E4. The room temperature is the mean of the measurements at the eight sampling points M1-M8. The cooling load is calculated by Equation 2. The 15 cases are randomly divided into two series (Series 1 and 2). Series 1 (Cases 1-7) is for the HRE model determination. Series 2 (Cases 8-15) is not involved in the model determination, but used for the model validation. The range of the supply air temperature in Series 1 is slightly broader than that in Series 2 and the range of the supply airflow rate in Series 1 is the same as that in Series 2. The supply air temperatures and supply airflow rates in Series 1 and 2 are the ones generally encountered in practice [19]. Thus, the HRE model validated is adequate for the air-side modulation in practice. The cooling load in Series 2 covers a wider range than that in Series 1, which will be used in Section 


\section{Applied Energy}

Volume 238, 15 March 2019, Pages 1237-1249

4.1 to show that the HRE model can be extrapolated to a wider range of the cooling load against the model determination.

Table 1. Experiment cases: Medium-sized stratum-ventilated classroom with mid-level exits.

\begin{tabular}{|c|c|c|c|c|c|c|}
\hline \multicolumn{2}{|c|}{ Cases } & $T_{\mathrm{s}}\left({ }^{0} \mathrm{C}\right)$ & $V_{\mathrm{s}}\left(\mathrm{m}^{3} / \mathrm{s}\right)$ & $Q_{\mathrm{cl}}(\mathrm{kW})$ & $T_{\mathrm{e}}\left({ }^{0} \mathrm{C}\right)$ & $T_{\mathrm{r}}\left({ }^{0} \mathrm{C}\right)$ \\
\hline \multirow{7}{*}{ Series 1} & 1 & 19.81 & 0.272 & 1.30 & 23.79 & 23.23 \\
\hline & 2 & 22.35 & 0.272 & 1.44 & 26.74 & 25.82 \\
\hline & 3 & 23.03 & 0.201 & 1.73 & 30.2 & 28.52 \\
\hline & 4 & 23.25 & 0.373 & 1.09 & 25.68 & 25.16 \\
\hline & 5 & 23.86 & 0.201 & 1.60 & 30.48 & 29.14 \\
\hline & 6 & 26.90 & 0.201 & 0.96 & 30.89 & 29.79 \\
\hline & 7 & 29.44 & 0.373 & 1.13 & 31.95 & 31.15 \\
\hline \multirow{8}{*}{ Series 2} & 8 & 21.87 & 0.373 & 1.44 & 25.07 & 24.58 \\
\hline & 9 & 23.72 & 0.201 & 1.76 & 31.02 & 29.13 \\
\hline & 10 & 22.24 & 0.272 & 1.89 & 28.01 & 26.8 \\
\hline & 11 & 23.03 & 0.201 & 1.73 & 30.2 & 28.52 \\
\hline & 12 & 24.99 & 0.272 & 1.79 & 30.45 & 29.17 \\
\hline & 13 & 25.30 & 0.373 & 1.98 & 29.71 & 28.63 \\
\hline & 14 & 26.32 & 0.373 & 1.87 & 30.48 & 29.55 \\
\hline & 15 & 26.41 & 0.373 & 0.52 & 27.58 & 27.22 \\
\hline
\end{tabular}

Note: Series 1 is for the HRE model determination, and Series 2 is not involved in the 
Applied Energy

Volume 238, 15 March 2019, Pages 1237-1249

model determination but used for the model validation.

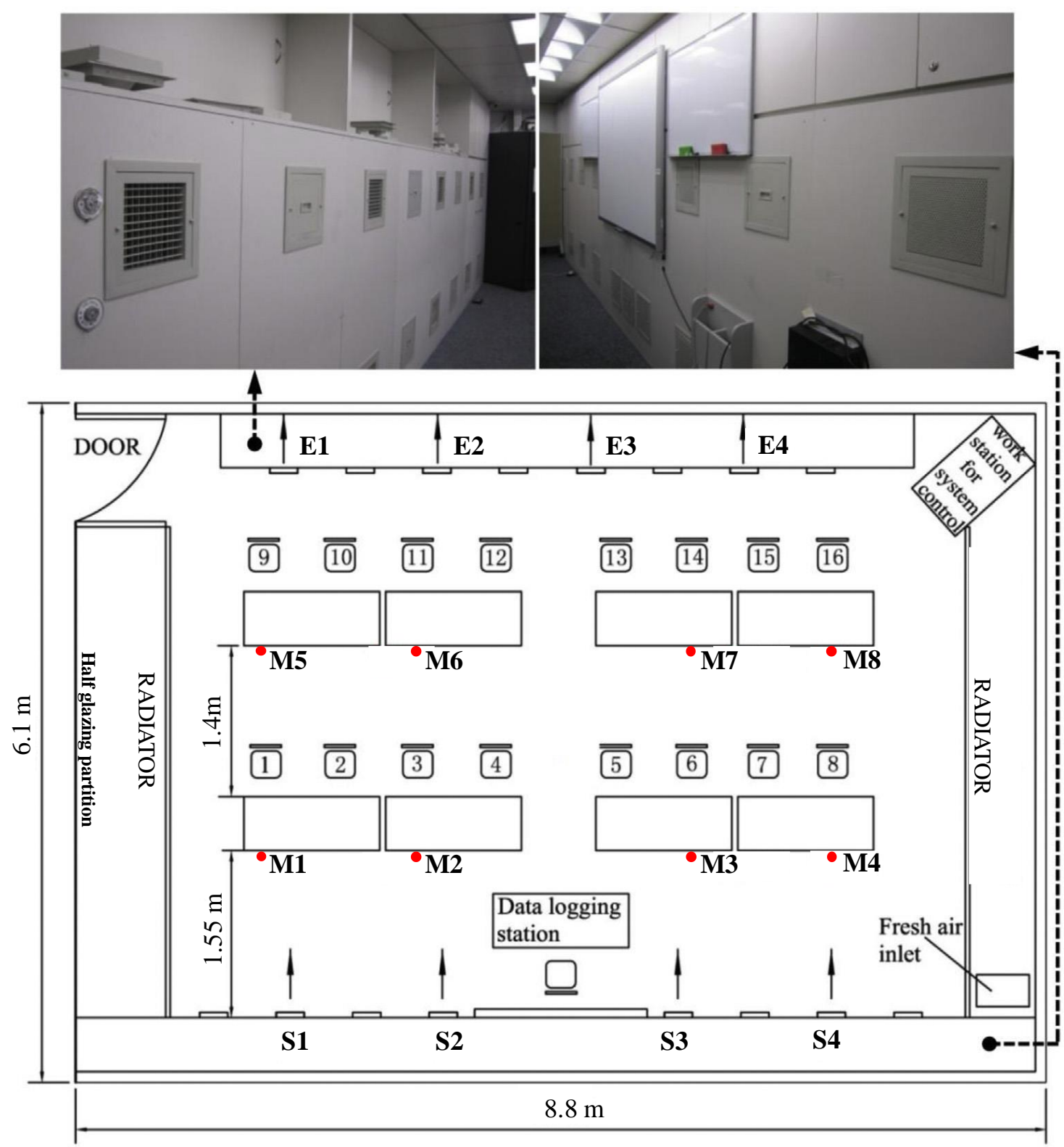

Note: $E$ and $S$ denote the exit louver and supply diffuser respectively at the height of $1.3 \mathrm{~m}$, and $M$ denotes the sampling point at the height of $1.1 \mathrm{~m}$.

Fig.2. Setup of medium-sized stratum-ventilated classroom with mid-level exits.

\subsection{Experiment in small-sized stratum-ventilated office with ceiling-level exit}

The small-sized stratum-ventilated office with ceiling-level exit is located in Xi'an Jiaotong University with dimensions of $3.8 \mathrm{~m}$ (length) $\times 2.8 \mathrm{~m}$ (width) $\times 2.6 \mathrm{~m}$ (height) (Figure 3). The office is designed for two occupants represented by two thermal manikins with dimensions of $400 \mathrm{~mm}$ (length) $\times 250 \mathrm{~mm}$ (width) $\times 1200 \mathrm{~mm}$ 


\section{Applied Energy}

Volume 238, 15 March 2019, Pages 1237-1249

(height). The east wall is imbedded with the electric heating film to simulate the glass façade [21], and the other walls, ceiling and floor are insulated. The heat generated by the electric heating film is adjusted to control the cooling load. The room temperature is measured at the height of $1.1 \mathrm{~m}$ (for seated occupants). Detailed information on the experimental setup and measurements are reported in Huan et al. [21]. A total of 13 cases (numbered 16 to 28) are designed for the thermal comfort environment with the room temperature varying from $25.10^{\circ} \mathrm{C}$ to $27.29^{\circ} \mathrm{C}$ (Table 2). The supply air temperature runs between $17^{\circ} \mathrm{C}$ and $21^{\circ} \mathrm{C}$, the supply airflow rate runs from $0.038 \mathrm{~m}^{3} / \mathrm{s}$ to $0.131 \mathrm{~m}^{3} / \mathrm{s}$, the cooling load runs from $0.47 \mathrm{~kW}$ to $1.41 \mathrm{~kW}$ (Equation 2), and the exit air temperature runs from $26.20^{\circ} \mathrm{C}$ to $30.97^{\circ} \mathrm{C}$. The 13 cases are also randomly divided into two series (Series 3 and 4). Series 3 (Cases 16-22) is for the HRE model determination. Series 4 (Cases 23-28) is not involved in the model determination, but used for the model validation.

Table 2. Experiment cases: Small-sized stratum-ventilated office with ceiling-level exit.

\begin{tabular}{|c|c|c|c|c|c|c|}
\hline \multicolumn{2}{|c|}{ Cases } & $T_{\mathrm{s}}\left({ }^{\circ} \mathrm{C}\right)$ & $V_{\mathrm{s}}\left(\mathrm{m}^{3} / \mathrm{s}\right)$ & $Q_{\mathrm{cl}}(\mathrm{kW})$ & $T_{\mathrm{e}}\left({ }^{\circ} \mathrm{C}\right)$ & $T_{\mathrm{r}}\left({ }^{\circ} \mathrm{C}\right)$ \\
\hline & 16 & 17 & 0.038 & 0.47 & 27.09 & 25.10 \\
\cline { 2 - 7 } & 17 & 17 & 0.078 & 1.29 & 30.64 & 26.17 \\
\cline { 2 - 7 } & 18 & 19 & 0.050 & 0.50 & 27.35 & 25.64 \\
\cline { 2 - 7 } & 19 & 19 & 0.085 & 1.06 & 29.43 & 26.35 \\
\cline { 2 - 7 } & 20 & 21 & 0.044 & 0.27 & 26.20 & 25.22 \\
\cline { 2 - 7 } & 21 & 21 & 0.088 & 0.76 & 28.15 & 26.15 \\
\cline { 2 - 7 } & 22 & 21 & 0.131 & 1.41 & 29.97 & 27.29 \\
\hline \multirow{5}{*}{ Series 3 4} & 17 & 0.055 & 0.69 & 27.39 & 25.10 \\
\cline { 2 - 7 } & 23 & 17 & 0.073 & 1.19 & 30.53 & 26.64 \\
\hline & 24 & 19 & 0.071 & 0.78 & 28.12 & 25.71 \\
\hline & 26 & 19 & 0.115 & 1.66 & 30.97 & 27.27 \\
\hline
\end{tabular}


Applied Energy

Volume 238, 15 March 2019, Pages 1237-1249

\begin{tabular}{|c|c|c|c|c|c|c|}
\hline & 27 & 21 & 0.069 & 0.54 & 27.48 & 25.89 \\
\cline { 2 - 7 } & 28 & 17 & 0.065 & 0.96 & 29.21 & 26.27 \\
\hline
\end{tabular}

Note: Series 3 is for the HRE model determination, and Series 4 is not involved in the model determination but used for the model validation.

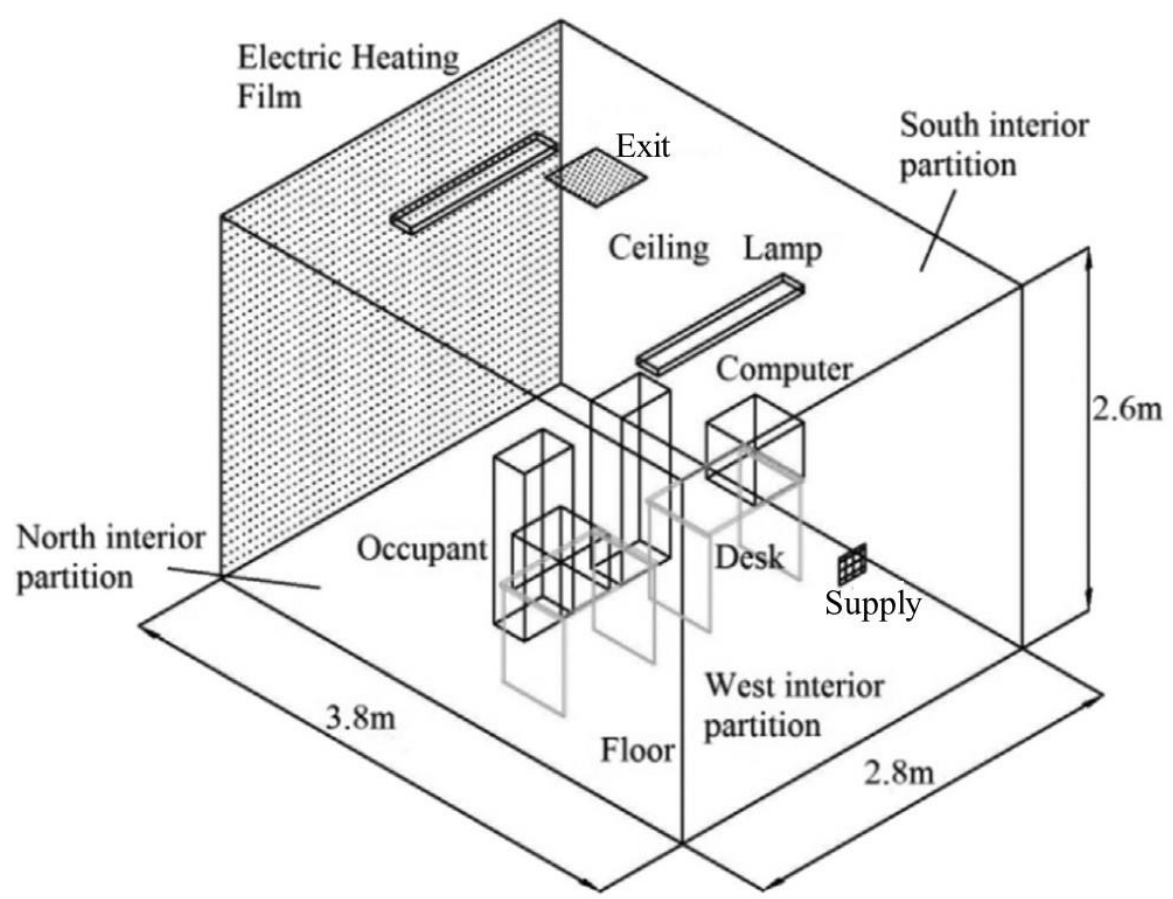

Fig.3. Setup of small-sized stratum-ventilated office with ceiling-level exit.

\section{HRE model development for two typical stratum-ventilated rooms}

\subsection{HRE model determination and validation: Medium-sized classroom with mid-level exits}

The three constant coefficients (i.e., $a, b$ and $c$ in Equation 3) for the HRE model of the medium-sized stratum-ventilated classroom with mid-level exits (Figure 2) are determined to be $1.737,-0.070$ and 0.766 respectively (Equation 4), with the regression coefficient $\mathrm{R}^{2}$ of 0.99 . Figure 4 shows the HREs predicted by Equation 4 agree reasonably well with the measurements. The errors of the predicted HREs for both Series 1 and 2 are within $\pm 5 \%$. The errors refer to the relative differences between the predicted and measured HREs. The mean absolute error of Series 1 is $2.21 \%$, and that of Series 2 is $1.95 \%$. The mean absolute error refers to the mean of the absolute values of errors [57]. Thus, the HRE model for this stratum-ventilated 
room is accurate.

$$
\frac{1}{H R E_{1}}=\frac{V_{\mathrm{s}}\left(1.737-0.070 T_{\mathrm{s}}\right)}{Q_{\mathrm{cl}}}+0.766
$$

where $H R E_{1}$ is the HRE model for the medium-sized stratum-ventilated classroom with mid-level exits.



Note: Series 1 and 2 (Table 1) refer to the stratum-ventilated classroom (Figure 2); Series 3 and 4 (Table 2) refer to the stratum-ventilated office (Figure 3). Error ( $\pm 5 \%$ ) indicates the relative difference between the predicted and measured values.

Fig.4. Comparisons between measured and predicted heat removal efficiencies of two typical stratum-ventilated rooms.

\subsection{HRE model determination and validation: Small-sized office with ceiling-level exit}

The three constant coefficients of $a, b$ and $c$ in Equation 3 for the HRE model of the small-sized stratum-ventilated office with ceiling-level exit (Figure 3) are determined to be $11.787,-0.432$ and 0.419 respectively (Equation 5), with the regression coefficient $R^{2}$ of 0.93 . The errors of the HREs predicted by Equation 5 for both Series 3 and 4 are within $\pm 5 \%$ (Figure 4). The mean absolute error of Series 3 is $2.7 \%$, and that of Series 4 is $2.5 \%$. Thus, the HRE model for this stratum-ventilated room is also accurate. 


\section{Applied Energy}

Volume 238, 15 March 2019, Pages 1237-1249

$$
\frac{1}{H R E_{2}}=\frac{V_{\mathrm{s}}\left(11.787-0.432 T_{\mathrm{s}}\right)}{Q_{\mathrm{cl}}}+0.419
$$

where $H R E_{2}$ is the HRE model for the small-sized stratum-ventilated office with ceiling-level exit.

\section{Analyses of applicability of proposed HRE model}

\subsection{Extrapolation to wider ranges of supply condition and cooling load}

The HRE model is extrapolated to wider ranges of the supply condition and cooling load to further test its applicability. For the cooling load, it is shown in Table 1 that the cases for the model validation which are not involved in the model determination (Series 2) cover a much wider range of the cooling load (i.e., $0.52 \mathrm{~kW}$ to $1.98 \mathrm{~kW}$ ) than that of the cases for the model determination (Series 1) (i.e., $0.96 \mathrm{~kW}$ to $1.73 \mathrm{~kW}$ ). The HREs of the cases for the model validation (Series 2) could be accurately predicted by the proposed HRE model (Equation 4) with errors within $\pm 5 \%$ and a mean absolute error of $1.95 \%$ (Section 3.1). Thus, the HRE model determined within a specific range of the cooling load can be extrapolated to a wider range of the cooling load.

For the supply condition, Cases 16-19, 23-25 and 28 (Table 2) are used to re-determine the HRE model. Cases 16-19, 23-25 and 28 cover a narrower range of the supply air temperature (i.e., $17^{\circ} \mathrm{C}$ to $19^{\circ} \mathrm{C}$ ) and supply airflow rate (i.e., 0.038 $\mathrm{m}^{3} / \mathrm{s}$ to $0.085 \mathrm{~m}^{3} / \mathrm{s}$ ). When using the re-determined model for predicting the HREs of Cases 16-28 covering a wider range of the supply air temperature from $17^{\circ} \mathrm{C}$ to $21^{\circ} \mathrm{C}$ and supply airflow rate from $0.038 \mathrm{~m}^{3} / \mathrm{s}$ to $0.131 \mathrm{~m}^{3} / \mathrm{s}$, the errors are within $\pm 5 \%$ except for Cases 17 and 22 (Figure 5). The errors of Case 17 and 22 are within $\pm 5.8 \%$ and $\pm 6.5 \%$ respectively which are also acceptable in practice. The mean absolute error for Cases 16-28 of the re-determined HRE model is 2.2\%, which is similar to that of the original HRE model (i.e., 2.6\%). The original HRE model is determined by cases (Series 3 in Table 2) covering a wider range of the supply air temperature (i.e., $17^{\circ} \mathrm{C}$ to $21^{\circ} \mathrm{C}$ ) and supply airflow rate (i.e., $0.038 \mathrm{~m}^{3} / \mathrm{s}$ to $0.131 \mathrm{~m}^{3} / \mathrm{s}$ ). Thus, the proposed HRE model determined by a narrower range of the supply condition and that determined by a wider range of the supply condition have 
Applied Energy

Volume 238, 15 March 2019, Pages 1237-1249

similar accuracy. This implies that the proposed HRE model determined by a certain range of the supply condition could be extrapolated to a wider range of the supply condition.

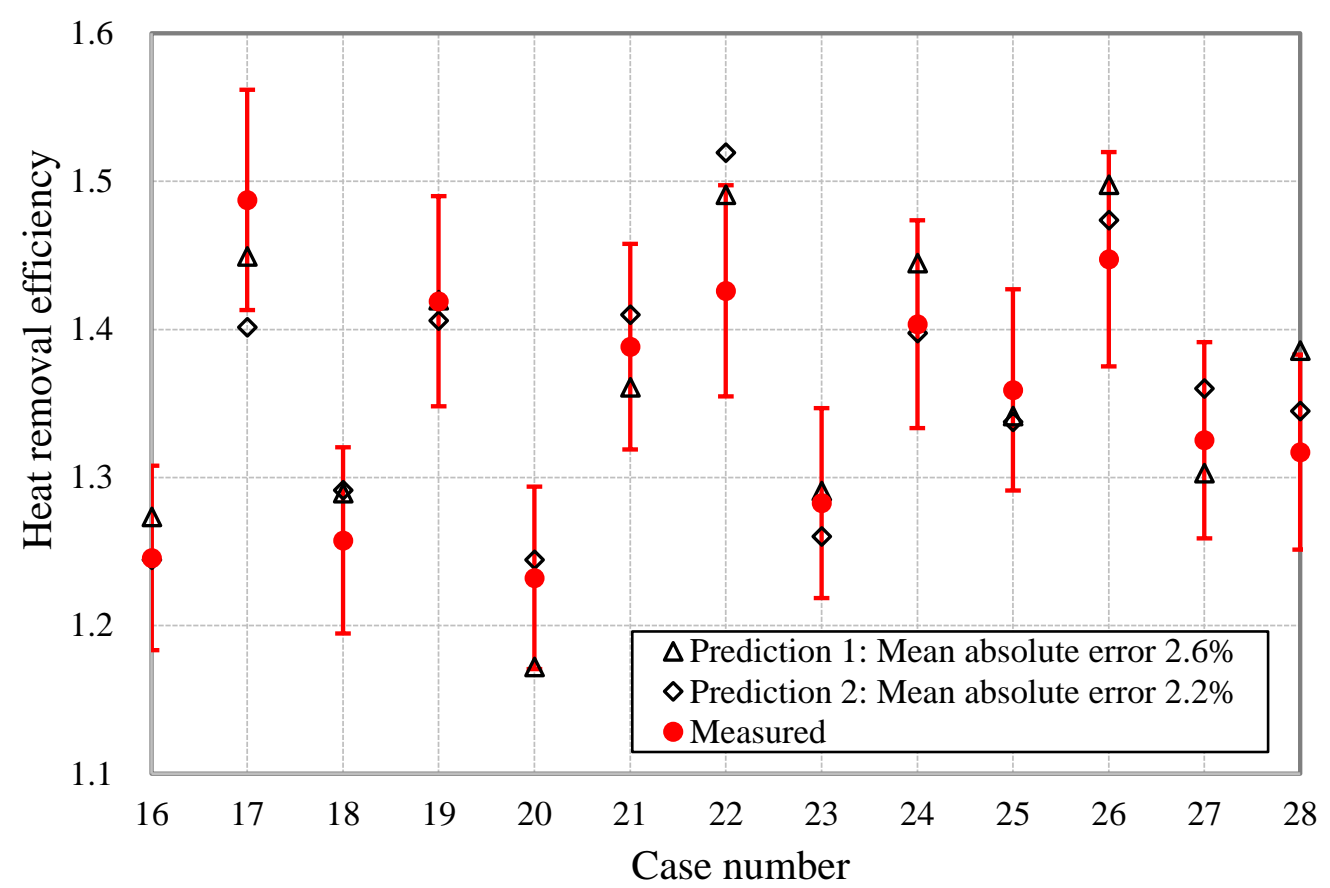

Note: Error bar of $\pm 5 \%$ indicates the relative difference between the predicted and measured values is within $\pm 5 \%$; cases for the model determination of Prediction 1 cover a wider range of the supply condition (Series 3 in Table 2); cases for the model determination of Prediction 2 cover a narrower range of the supply condition (Cases 16-19, 23-25 and 28 in Table 2).

Fig.5. Comparisons between measured and predicted heat removal efficiencies of small-sized stratum-ventilated office with ceiling-level exit.

\subsection{Extension to displacement ventilation}

Two displacement ventilation systems in Delft University of Technology are considered with the room dimensions of $5.6 \mathrm{~m}$ (length) $\times 3.0 \mathrm{~m}$ (width) $\times 3.2 \mathrm{~m}$ (height) (Figure 6) [44]. The supply and exit air terminals are on the same side for System 1, and on the opposite sides for System 2. On the other hand, the heat source is placed on the opposite side to the supply air terminal for System 1, and on the same side for System 2. The heat source is located on the window to simulate the solar radiation. Ten cases (numbered 29 to 38 in Table 3) are extracted from the 


\section{Applied Energy}

Volume 238, 15 March 2019, Pages 1237-1249

experiments and CFD simulations of Chen et al. [44]. The supply air temperature runs from $16.0^{\circ} \mathrm{C}$ to $20.8^{\circ} \mathrm{C}$, the supply airflow rate runs from $0.04 \mathrm{~m}^{3} / \mathrm{s}$ to $0.10 \mathrm{~m}^{3} / \mathrm{s}$, the cooling load runs from $0.50 \mathrm{~kW}$ to $0.94 \mathrm{~kW}$ (Equation 2), the exit air temperature runs from $24.8^{\circ} \mathrm{C}$ to $27.1^{\circ} \mathrm{C}$, and the room temperature is maintained around $23.5^{\circ} \mathrm{C}$ (between $22.9^{\circ} \mathrm{C}$ and $23.8^{\circ} \mathrm{C}$ ). The room temperature is measured at the height of 1.6 m (for standing occupants). Cases 29-36 are for System 1 and the remaining two cases are for System 2. More information about the experiments and CFD simulations could be found in Chen et al. [44]. The 10 cases are divided into two series (Series 5 and 6). Series 5 (Cases 29-34) is used for the HRE model determination. Series 6 (Cases 35-38) is not involved in the model determination, but used for the model validation.

Table 3. Experiment and simulation cases: Displacement ventilation [44].

\begin{tabular}{|c|c|c|c|c|c|c|c|c|}
\hline \multicolumn{2}{|c|}{ Cases } & System & $\begin{array}{c}\text { Data } \\
\text { source }\end{array}$ & $\begin{array}{c}T_{\mathrm{s}} \\
\left({ }^{0} \mathrm{C}\right)\end{array}$ & $\begin{array}{c}V_{\mathrm{s}} \\
\left(\mathrm{m}^{3} / \mathrm{s}\right)\end{array}$ & $\begin{array}{c}Q_{\mathrm{cl}} \\
(\mathrm{kW})\end{array}$ & $\begin{array}{c}T_{\mathrm{e}} \\
\left({ }^{0} \mathrm{C}\right)\end{array}$ & $\begin{array}{c}T_{\mathrm{r}} \\
\left({ }^{0} \mathrm{C}\right)\end{array}$ \\
\hline \multirow{6}{*}{ Series 5} & 29 & 1 & Exp & 16.0 & 0.04 & 0.52 & 25.6 & 23.8 \\
\hline & 30 & 1 & Exp & 19.7 & 0.07 & 0.48 & 25.0 & 23.2 \\
\hline & 31 & 1 & Exp & 20.8 & 0.10 & 0.50 & 24.8 & 22.9 \\
\hline & 32 & 1 & Exp & 19.6 & 0.10 & 0.94 & 27.1 & 23.8 \\
\hline & 33 & 1 & CFD & 16.0 & 0.04 & 0.53 & 25.8 & 23.5 \\
\hline & 34 & 1 & CFD & 19.1 & 0.07 & 0.53 & 25.0 & 23.4 \\
\hline \multirow{4}{*}{ Series 6} & 35 & 1 & CFD & 20.7 & 0.10 & 0.53 & 24.9 & 23.4 \\
\hline & 36 & 1 & CFD & 19.4 & 0.10 & 0.94 & 26.9 & 23.7 \\
\hline & 37 & 2 & Exp & 19.3 & 0.07 & 0.51 & 25.0 & 23.2 \\
\hline & 38 & 2 & CFD & 18.7 & 0.07 & 0.55 & 24.8 & 23.2 \\
\hline
\end{tabular}

Note: Exp denotes experiment; Series 5 is for the HRE model determination, and Series 6 is not involved in the model determination but used for the model validation.

The three constant coefficients of $a, b$ and $c$ (Equation 3) for the HRE model of System 1 are determined as $21.533,-0.970$ and 0.276 respectively, with the regression coefficient $\mathrm{R}^{2}$ of 0.82 (Equation 6). Figure 6 shows the predicted HREs by Equation 
Applied Energy

Volume 238, 15 March 2019, Pages 1237-1249

6 agree reasonably well with the results reported by Chen et al. [44]. The errors of the predicted HREs for cases of System 1 (Cases 29-36) are within $\pm 5 \%$, except Cases 31 and 35 . The errors of Cases 31 and 35 are $6.2 \%$ and $13.7 \%$ respectively. The large error of Case 35 is caused by the small difference between the supply air temperature and room temperature $\left(2.7^{\circ} \mathrm{C}\right.$ in Table 3$)$. With such a small difference between the supply air temperature and room temperature, a variation of $0.33^{\circ} \mathrm{C}$ in the room temperature can result in a variation of $13.7 \%$ in the HRE (Equation 1). Thus, the error is also common and acceptable for engineering applications. The mean absolute error of the predicted HREs for System 1 is $3.8 \%$. Thus, the proposed HRE model is accurate for System 1.

$$
\frac{1}{H R E_{3}}=\frac{V_{\mathrm{s}}\left(21.533-0.970 T_{\mathrm{s}}\right)}{Q_{\mathrm{cl}}}+0.276
$$

where $\mathrm{HRE}_{3}$ is the HRE model for System 1 of displacement ventilation.

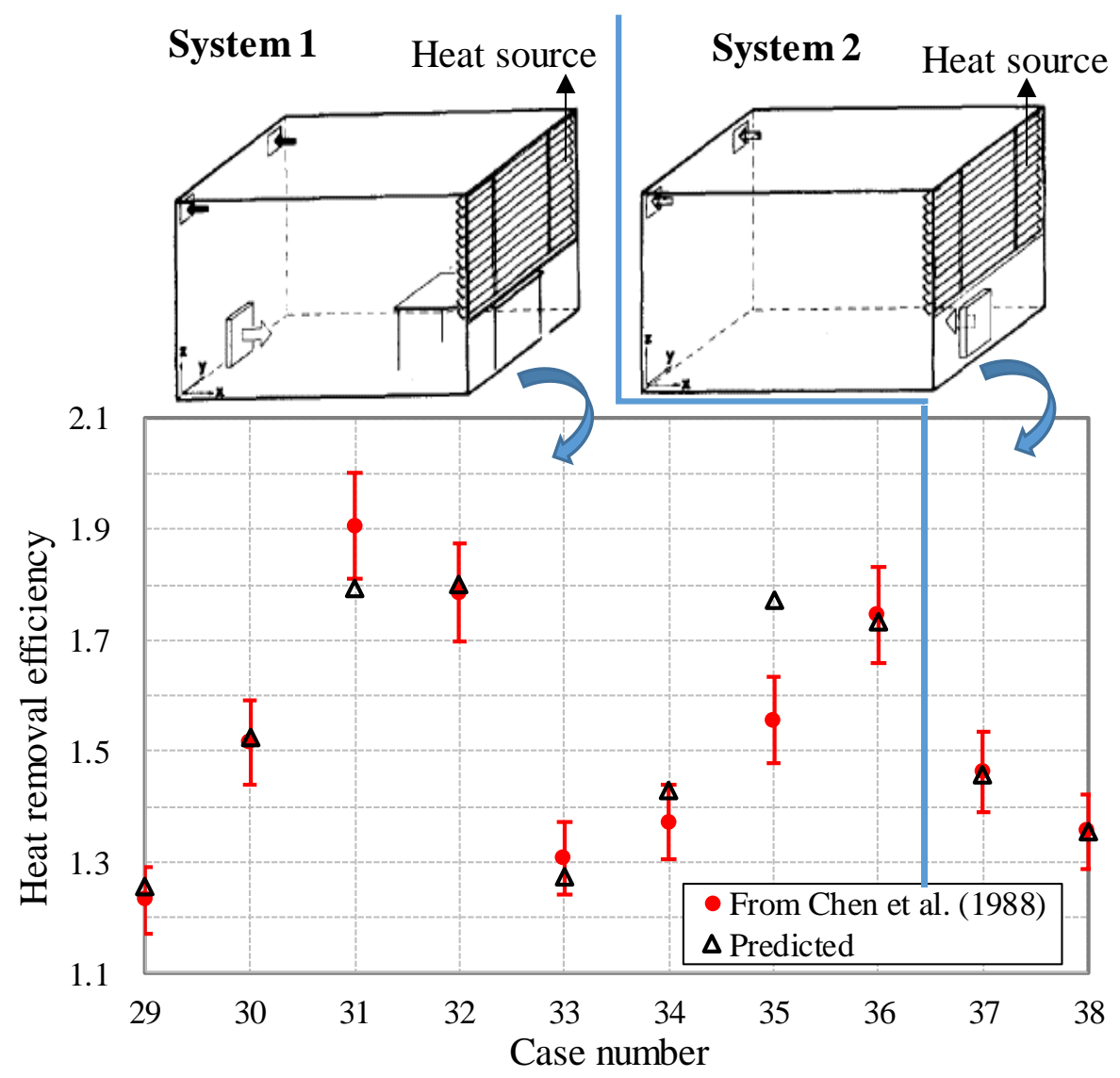

Note: Error bar of $\pm 5 \%$ indicates the relative difference between the predicted value and data reported by Chen et al. [44] is within $\pm 5 \%$.

Fig.6. Comparisons between heat removal efficiencies of two displacement 
Applied Energy

Volume 238, 15 March 2019, Pages 1237-1249

ventilation systems predicted by HRE model and reported by Chen et al. [44].

The proposed HRE model of System 1 (Equation 6) is also tested for System 2 (Cases 37 and 38). The predicted HREs are in fairly good agreement with the data given by Chen at al. [44] with errors within $\pm 1 \%$ (Figure 6). Although the configurations of the air terminals and heat sources are important in airflow computations, the same HRE model with the same constant coefficients is shared by the two different displacement ventilation systems. This might be attributed to the similar airflow pattern of Systems 1 and 2, which is consistent with the results of Chen at al. [44] and Lin et al. [58]. Summarily, the above analyses imply that the proposed HRE model is applicable to displacement ventilation. More experimental data can be found in the literature to support the proposed HRE model (Equation 3), e.g., the experiments on displacement ventilation for cooling in The University of Hong Kong [59] and displacement ventilation with floor heating in Technical University of Denmark [27]. However, considering the lengthy, no more repeated validations on the HRE model (Equation 3) are presented in this paper.

As a summary, for a given room with specific room geometries and air terminal configurations, the proposed HRE model can be determined as the function of the supply air temperature, supply airflow rate and cooling load by quantifying the three constant coefficients in Equation 3. The determined HRE is promising for a wider range of the supply air temperature, supply airflow rate and cooling load against the model determination. For substantially different rooms, the three constant coefficients are recommended to be re-determined (e.g., Figures 2 and 3). The HRE models of two typical stratum-ventilated rooms and two displacement-ventilated rooms have been determined (Equations 4-6). The HRE models for more stratum-ventilated and displacement-ventilated rooms generally encountered in practice, e.g., stratum ventilation with the supply and exit air terminals on the same wall $[60,61]$, should be prepared to form the database of HRE models in future studies. For different stratum-ventilated/displacement-ventilated rooms in practice, the corresponding HRE models can be selected from the database and used for the air-side modulation. The air-side modulation using the HRE model is illustrated in the following two sections. 


\section{Applied Energy}

Volume 238, 15 March 2019, Pages 1237-1249

\section{Applications of HRE to air-side modulation for thermal comfort}

The modified PMV (Equation 7) can be used for the thermal comfort evaluation of stratum ventilation [37], which is explained as follows. For occupants with typical summer clothing and sedentary activity, the PMV given by ASHRAE 55-2017 [45] is expressed to be the function of the room temperature and air velocity using multiple regression analysis. The mean radiant temperature is assumed to be the same as the room temperature $[18,45]$ and the relative humidity is assumed to be $58.5 \%$. Chow et al. [62] experimentally confirmed that when the relative humidity was between $50 \%$ and $80 \%$, the variation of the relative humidity imposed insignificant effects on thermal comfort. The air velocity is further correlated to the room temperature and supply airflow rate by multiple regression analysis. By replacing the air velocity in the PMV with the room temperature and supply airflow rate, the PMV model is modified to be the function of the room temperature and supply airflow rate. Equation 7 has been experimentally validated to be applicable to the two stratum-ventilated rooms (Figures 2 and 3) [37]. More details about the modified PMV can be found in Zhang et al. [37]. The supply airflow rate could be readily read from the building management system, while the room temperature for collective air distributions with a non-uniform thermal environment is difficult to predict (Section 1). In other words, to modulate the air-side for thermal comfort, the room temperature prediction is the core issue. Thus, the room temperature prediction for thermal comfort is the focus of this section.

$$
P M V=-\frac{7}{91300} N T_{\mathrm{r}}^{2}+\frac{19}{50} T_{\mathrm{r}}-\frac{689}{74}
$$

where $P M V$ is the Predicted Mean Vote; $N$ is the supply airflow rate in term of air changes per hour $(\mathrm{ACH})$.

Figure 7 compares the room temperatures predicted by the HRE model proposed with the experiments and CFD simulations for the two typical stratum-ventilated rooms and two displacement ventilation systems (Tables 1-3). The HRE model predicts the room temperature by solving equations 1,2 and 4/5/6 with the inputs of the supply condition and exit air temperature (Tables 1, 2 and 3). A wide range of the room temperature is covered, running from around $23{ }^{\circ} \mathrm{C}$ to $31^{\circ} \mathrm{C}$. The errors of the room temperature prediction are generally within $\pm 0.3{ }^{\circ} \mathrm{C}$ except Cases 28 and 35 . The 
Applied Energy

Volume 238, 15 March 2019, Pages 1237-1249

errors for Cases 28 and 35 is $-0.45^{\circ} \mathrm{C}$ and $-0.33^{\circ} \mathrm{C}$ respectively. The mean absolute error of all the predicted room temperatures is $0.12^{\circ} \mathrm{C}$, which meets the requirements for thermal comfort evaluation [63]. The good agreement of the predicted room temperatures with the experiments and CFD simulations can be explained by the accuracy of the HRE model proposed (Sections 3 and 4). Therefore, in the following investigations on the air-side modulation, the HREs and room temperatures predicted by the HRE model are regarded as accurate.

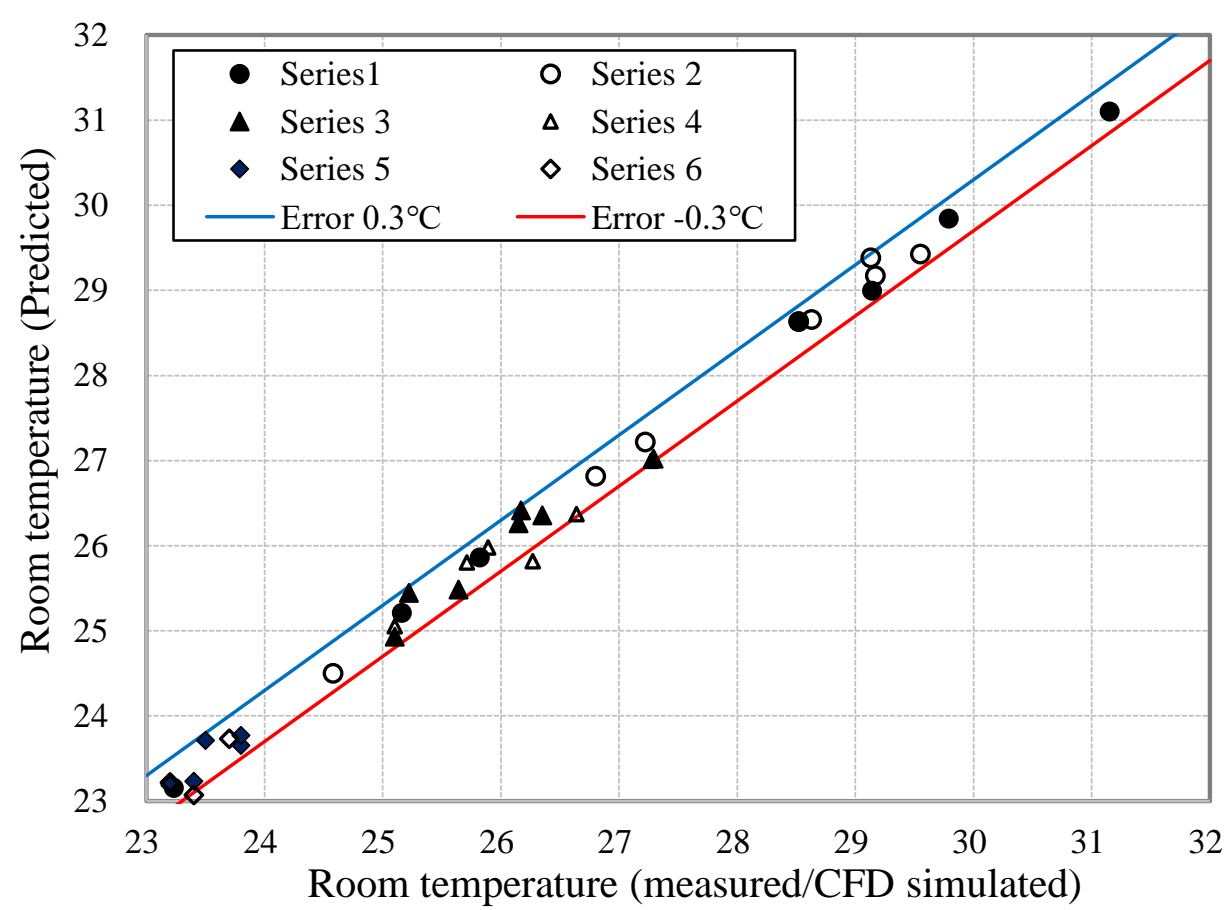

Note: Series 1 and 2 (Table 1) refer to the stratum-ventilated classroom (Figure 2); Series 3 and 4 (Table 2) refer to the stratum-ventilated office (Figure 3); Series 5 and 6 (Table 3) refer to the two displacement ventilation systems (Figure 6); error $\left( \pm 0.3^{0} \mathrm{C}\right.$ ) indicates the difference between the HRE-model-predicted and measured/CFD simulated values.

Fig.7. Comparisons of HRE-model-predicted and measured/CFD simulated room temperatures.

The following investigations on the air-side modulation for the two typical stratum-ventilated rooms cover a wide range of the supply condition and cooling load. The cooling load runs from $30 \mathrm{~W} / \mathrm{m}^{2}$ to $130 \mathrm{~W} / \mathrm{m}^{2}$ [21]. To minimize draft risk, the supply air temperature is between $21^{\circ} \mathrm{C}$ and $25^{\circ} \mathrm{C}$ for the constant-air-volume system, and the supply airflow rate is from $7 \mathrm{ACH}$ to $15 \mathrm{ACH}$ for the variable-air-volume 


\section{Applied Energy}

Volume 238, 15 March 2019, Pages 1237-1249

system [19]. PMV (Equation 7) is restricted within \pm 0.5 for thermal comfort $[18,37$, 45].

\subsection{Room temperature modulation: Medium-sized classroom with mid-level exits}

Figure 8 shows variations of the HRE with supply conditions and cooling loads of the medium-sized stratum-ventilated classroom with mid-level exits. The HRE outside the thermally workable zone is excluded. With a low supply air temperature and small cooling load, PMV would be lower than -0.5 ; and on the contrary, PMV would be higher than 0.5 , which is outside the thermally workable zone of the constant-air-volume system. Similarly, with a high supply airflow rate and small cooling load, PMV would be lower than -0.5 ; and on the contrary, PMV would be higher than 0.5, which is outside the thermally workable zone of the variable-air-volume system. With a supply airflow rate setting of $11 \mathrm{ACH}$ [19], the constant-air-volume system can serve a cooling load running from $30 \mathrm{~W} / \mathrm{m}^{2}$ to 70 $\mathrm{W} / \mathrm{m}^{2}$. With a supply air temperature setting of $21^{\circ} \mathrm{C}$ [19], the variable-air-volume system can serve a cooling load ranging from $30 \mathrm{~W} / \mathrm{m}^{2}$ to $125 \mathrm{~W} / \mathrm{m}^{2}$. It is noted that the specific range of the cooling load which the constant-air-volume system and variable-air-volume system can serve is affected by the supply airflow rate setting and supply air temperature setting respectively (Equation 7). The constant-air-volume system serves a narrower range of the cooling load than the variable-air-volume system because PMV is more sensitive to the supply air temperature than to the supply airflow rate (Equation 7) [64]. For the constant-air-volume system, the HRE increases from around 1.22 to 1.31 with the increasing cooling load and supply air temperature. For the variable-air-volume system, the HRE increases from around 1.22 to 1.27 with the increasing cooling load and decreasing supply airflow rate. Thus, the variations of the HRE for both the two systems are small, which indicates that a properly assumed constant HRE is adequate for the air-side modulation of the room temperature for thermal comfort. 


\section{Applied Energy}

Volume 238, 15 March 2019, Pages 1237-1249

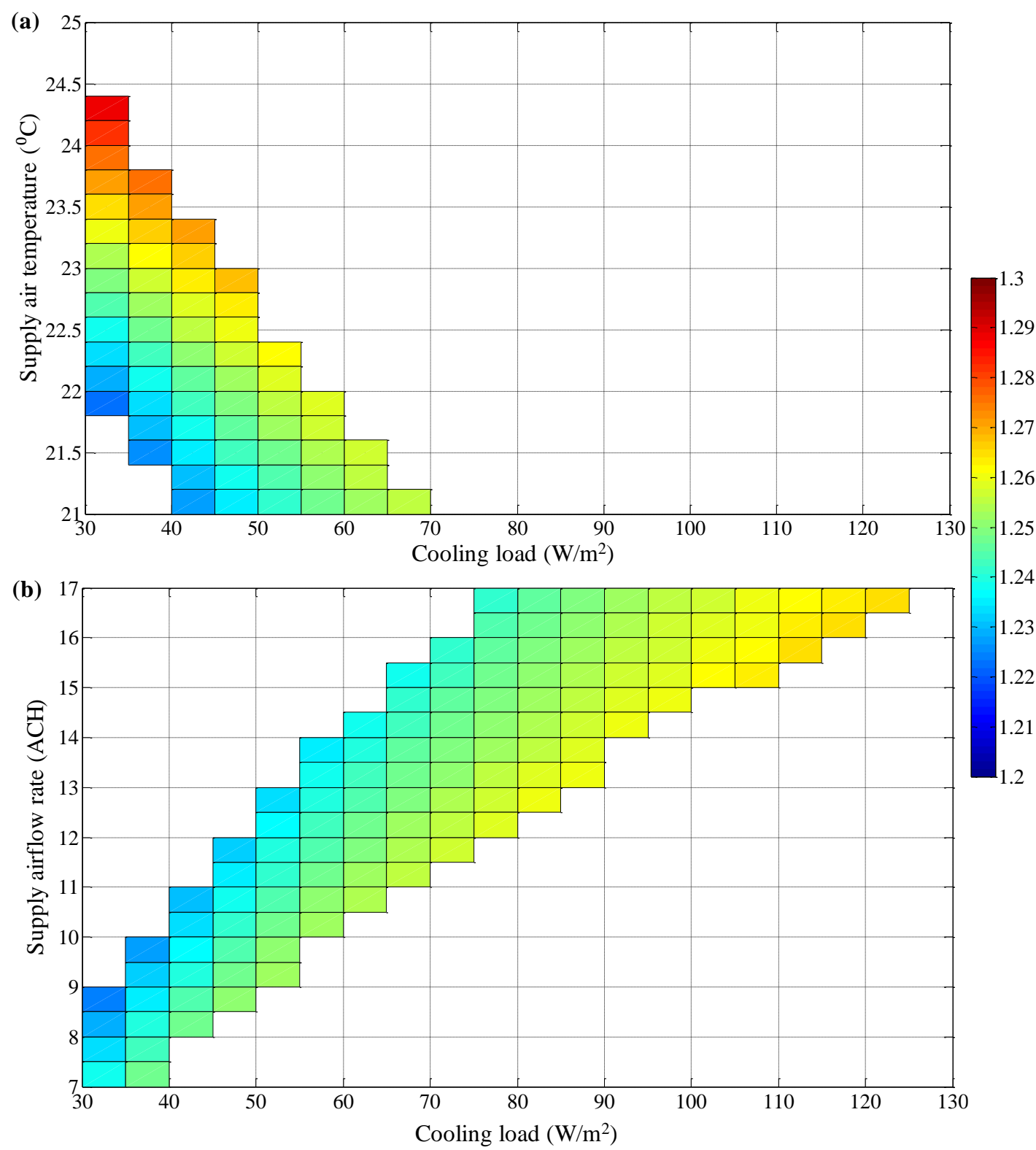

Note: HRE is calculated by the validated HRE model (Equation 4).

Fig.8. Variations of heat removal efficiencies with supply conditions and cooling loads of medium-sized stratum-ventilated classroom with mid-level exits: (a) Constant-air-volume system; and (b) variable-air-volume system.

With the conventionally used constant HRE, i.e., 1.38 [25, 35-37], the error of the room temperature prediction runs from around $-0.55^{\circ} \mathrm{C}$ to $-0.14^{0} \mathrm{C}$ and from around $-0.62^{\circ} \mathrm{C}$ to $-0.39^{\circ} \mathrm{C}$ for the constant-air-volume and variable-air-volume systems respectively (Figure 9). The error of the room temperature prediction is calculated as the room temperature deviation between the predictions by the conventionally used constant HRE and the proposed HRE model (Equation 4). The larger error range of 
Applied Energy

Volume 238, 15 March 2019, Pages 1237-1249

the room temperature for the constant-air-volume system is caused by the larger variation of the HRE when compared with that for the variable-air-volume system. On the other hand, it is seen that by properly assuming the value of the constant HRE, the error of the room temperature prediction could be maintained within $\pm 0.25^{\circ} \mathrm{C}$ and $\pm 0.15^{\circ} \mathrm{C}$ for the constant-air-volume and variable-air-volume systems respectively which are acceptable in practice for thermal comfort. However, with different designs of these two systems (i.e., the supply airflow rate setting for the constant-air-volume system, and the supply air temperature setting for the variable-air-volume system), the proper constant HRE can be substantially different (Figure 4). The proper constant HRE can be calculated by the proposed HRE model.



Note: Room temperature deviation is the error in room temperature prediction by the 
Applied Energy

Volume 238, 15 March 2019, Pages 1237-1249

conventionally assumed constant HRE of 1.38 .

Fig.9. Variations of room temperature deviations with supply conditions and cooling loads of medium-sized stratum-ventilated classroom with mid-level exits: (a) Constant-air-volume system; and (b) variable-air-volume system.

\subsection{Room temperature modulation: Small-sized office with ceiling-level exit}

Figure 10 shows variations of the HRE with supply conditions and cooling loads of the small-sized stratum-ventilated office with ceiling-level exit. With a supply airflow rate setting of $11 \mathrm{ACH}$ [19], the constant-air-volume system can serve a cooling load running from $30 \mathrm{~W} / \mathrm{m}^{2}$ to $90 \mathrm{~W} / \mathrm{m}^{2}$. With a supply air temperature setting of $21^{\circ} \mathrm{C}$ [19], the variable-air-volume system can serve all considered cooling loads $\left(30 \mathrm{~W} / \mathrm{m}^{2}\right.$ to $130 \mathrm{~W} / \mathrm{m}^{2}$ ). For the constant-air-volume system, the HRE increases from around 0.88 to 1.58 with the increasing cooling load and supply air temperature. For the variable-air-volume system, the HRE increases from around 0.88 to 1.60 with the increasing cooling load and decreasing supply airflow rate. Thus, the variations of the HRE for both the two systems are large, which indicates that an assumed constant HRE would lead to a poor air-side modulation of room temperature for thermal comfort. 


\section{Applied Energy}

Volume 238, 15 March 2019, Pages 1237-1249

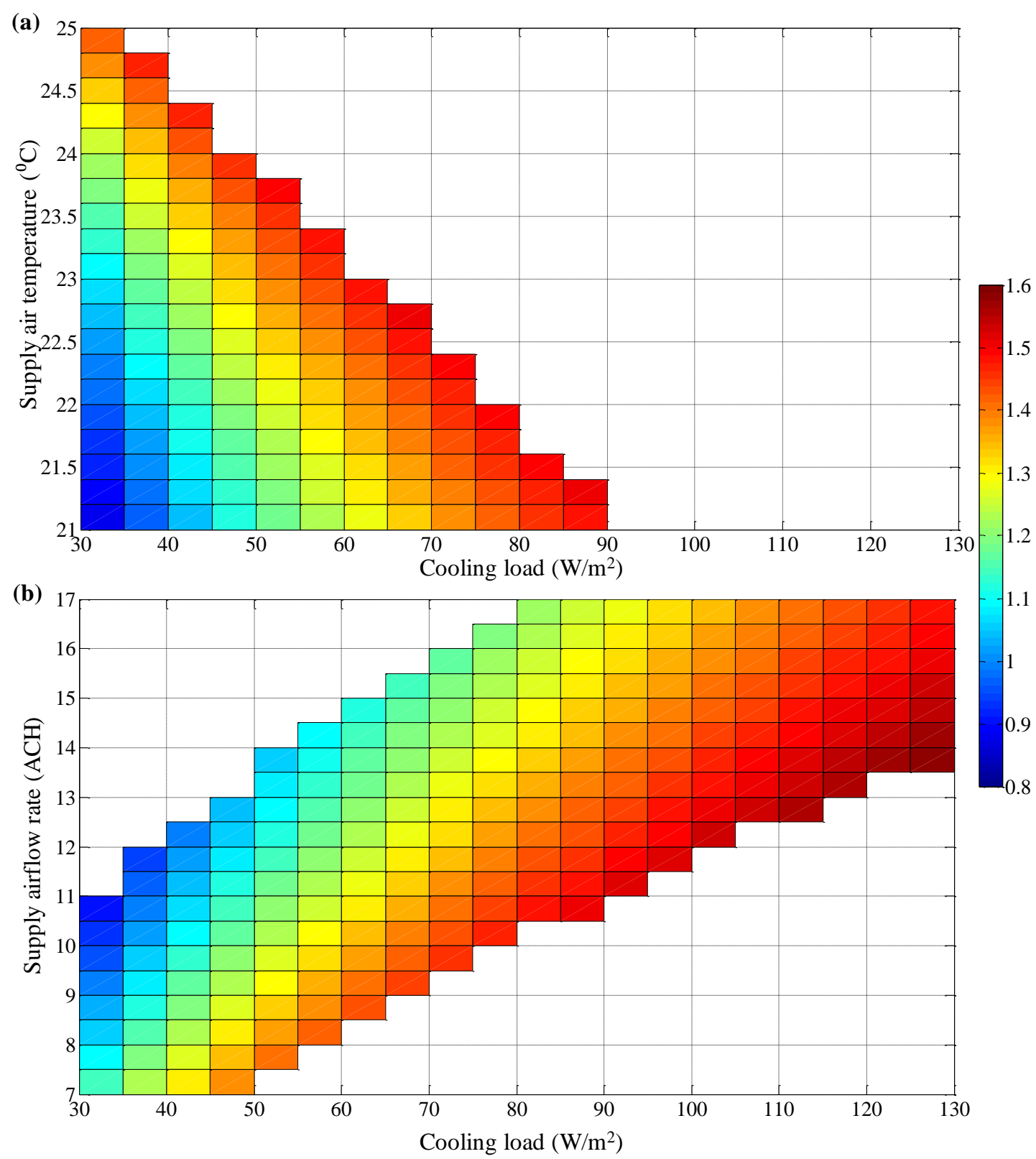

Note: HRE is calculated by the validated HRE model (Equation 5).

Fig.10. Variations of heat removal efficiencies with supply conditions and cooling loads of small-sized stratum-ventilated office with ceiling-level exit: (a) Constant-air-volume system; and (b) variable-air-volume system.

With the conventionally used constant HRE of 1.38 [25, 35-37], the error of the room temperature prediction runs from $-1.30^{\circ} \mathrm{C}$ to $0.78^{\circ} \mathrm{C}$ and from $-1.30^{\circ} \mathrm{C}$ to $1.13^{\circ} \mathrm{C}$ for the constant-air-volume system and variable-air-volume system respectively (Figure 11). The error of the room temperature prediction is calculated as the room temperature deviation between the predictions by the conventionally used constant 
Applied Energy

Volume 238, 15 March 2019, Pages 1237-1249

HRE and the proposed HRE model (Equation 5). The larger error range of the room temperature prediction by the conventionally used constant HRE for the variable-air-volume system can be explained by the larger variation of the HRE when compared with the constant-air-volume system. It is seen that by properly assuming the value of the constant HRE, the error of the room temperature prediction could be maintained within $\pm 1.1^{\circ} \mathrm{C}$ and $\pm 1.3^{\circ} \mathrm{C}$ for the constant-air-volume system and variable-air-volume system respectively. An error in the room temperature prediction of $\pm 1.1^{\circ} \mathrm{C}$ can result in an unacceptable error in the prediction of PMV (Equation 7), which reveals the deficiency of a constant HRE for the air-side modulation of room temperature for thermal comfort. Thus, in practice, the HRE model proposed is needed for the air-side modulation of room temperature for thermal comfort. 

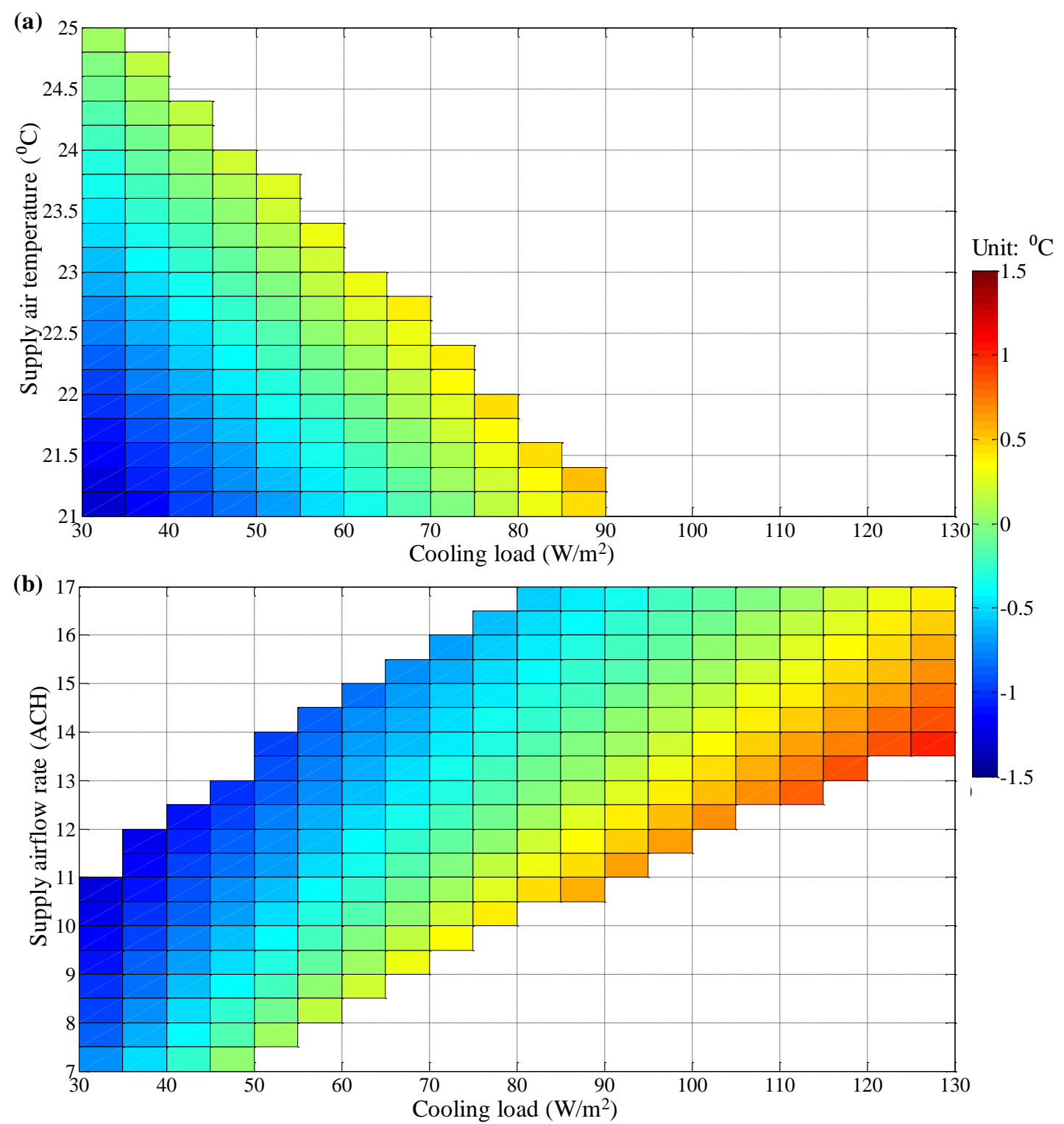

Note: Room temperature deviation is the error in room temperature prediction by the conventionally used constant HRE of 1.38 .

Fig.11. Variations of room temperature deviations with supply conditions and cooling loads of small-sized stratum-ventilated office with ceiling-level exit: (a) Constant-air-volume system; and (b) variable-air-volume system.

Compared with the medium-sized stratum-ventilated classroom with mid-level exits, the HRE variation range of the small-sized stratum-ventilated office with ceiling-level exit is much wider, which may be caused by the differences in airflow pattern stability due to the different exit air terminal layouts and/or room geometries. It is mainly caused by the different exit air terminal layouts. For the stratum-ventilated classroom, the exit louvers are located on the wall at the height of $1.3 \mathrm{~m}$, while the exit of the 
Applied Energy

Volume 238, 15 March 2019, Pages 1237-1249

stratum-ventilated office is located on the ceiling. Due to the thermal buoyancy effect, the exit air temperature of the stratum-ventilated office is significantly different from the room temperature (at the height of $1.1 \mathrm{~m}$ ), which leads to the large variation of the HRE. While for the stratum-ventilated classroom, because the exit louvers are close to the height of $1.1 \mathrm{~m}$ in the occupied zone, the thermal buoyancy effect on the exit air temperature is small and the exit air temperature is close to the room temperature. Thus, the variation of the HRE of the stratum-ventilated classroom is small. Summarily, the above results demonstrate the importance and effectiveness of the proposed HRE model in the air-side modulation for thermal comfort.

\section{Applications of HRE to air-side modulation for improving energy efficiency while maintaining thermal comfort}

The proposed HRE model based air-side modulation can be used to improve the energy efficiency of the air conditioning system by maximizing the HRE while maintaining thermal comfort [10, 39, 40]. A larger HRE indicates a higher energy efficiency $[10,39,40]$. Thus, maximizing the $\mathrm{HRE}$ is a convenient and straightforward method for improving the energy efficiency of the air conditioning system [18, 41-43], which is particularly useful when the detailed information of the energy consumption of the air conditioning system is not available.

The potential for energy efficiency improvement of the proposed HRE model based air-side modulation can be demonstrated by the maximal HRE difference for the same cooling load. The maximal HRE difference is defined as the difference between the maximal and minimal HREs for the same cooling load (Equation 8). The maximal value of HRE for a particular cooling load is the HRE value that can be achieved by the proposed HRE model based air-side modulation. The minimal value of the HRE for that particular cooling load is the worst HRE value that can be encountered in practice. Thus, a larger maximal HRE difference of the same cooling load indicates a larger energy efficiency improvement potential by the proposed HRE model based air-side modulation. For example, as shown in Figure 10(a), when the cooling load is $60 \mathrm{~W} / \mathrm{m}^{2}$, the proposed HRE model based air-side modulation determines the supply air temperature to be $23.4^{\circ} \mathrm{C}$ to achieve the maximal HRE of 1.56 . Without the modulation, the supply air temperature might be determined as $21{ }^{\circ} \mathrm{C}$ with the minimal 
Applied Energy

Volume 238, 15 March 2019, Pages 1237-1249

HRE of 1.28. Thus the corresponding maximal HRE difference is $21.9 \%$. It is noted that the maximal HRE difference for the same cooling load is calculated while thermal comfort is maintained. For thermal comfort, PMV is limited to \pm 0.5 in the following analyses and the supply air temperature is constrained to be not less than $21^{0} \mathrm{C}$ to minimize draft risk [19].

$$
\text { Maximal } H R E \text { difference }=\frac{H R E_{\max }-H R E_{\min }}{H R E_{\min }}
$$

where $H R E_{\max }$ and $H R E_{\min }$ are the maximal and minimal HREs for the same cooling load respectively.

For the stratum-ventilated office (Figure 3), the maximal HRE difference for the same cooling load with the constant-air-volume system (calculated from Figure 10a) varies between $2.4 \%$ and $67.3 \%$ (Figure 12) when the cooling load varies from $30 \mathrm{~W} / \mathrm{m}^{2}$ to $90 \mathrm{~W} / \mathrm{m}^{2}$. The maximal HRE difference for the same cooling load of the variable-air-volume system (calculated from Figure 10b) varies from $8.5 \%$ to $39.6 \%$ when the cooling load varies between $30 \mathrm{~W} / \mathrm{m}^{2}$ and $130 \mathrm{~W} / \mathrm{m}^{2}$. The maximal HRE difference for the cooling load larger than $90 \mathrm{~W} / \mathrm{m}^{2}$ of the constant-air-volume system does not exist, because the constant-air-volume system cannot provide thermal comfort (Figure 10a). For the constant-air-volume system, the maximal HRE difference for the same cooling load decreases with the increasing cooling load. This is because that the options of the supply air temperature meeting the requirement of thermal comfort decrease with the increasing cooling load (Figure 10a). For the variable-air-volume system, the maximal HRE difference for the same cooling load increases first and then decreases with the increasing cooling load. This is because when the cooling load is extremely low or high, fewer options of the supply airflow rate can satisfy the requirement of thermal comfort (Figure 10b). With the maximal HRE difference of the same cooling load for the constant-air-volume system and variable-air-volume system up to $67.3 \%$ and $39.6 \%$ respectively, the proposed HRE model based air-side modulation is effective in energy saving while maintaining thermal comfort for this stratum-ventilated office. 
Volume 238, 15 March 2019, Pages 1237-1249



Note: A larger maximal HRE difference (Equation 8) indicates a larger energy saving potential by the proposed HRE model based air-side modulation.

Fig.12. Variations of maximal HRE difference with cooling loads of two typical stratum-ventilated rooms.

With regards to the stratum-ventilated classroom (Figure 2), the maximal HRE difference of the same cooling load for the constant-air-volume system runs from $0.2 \%$ to $6.7 \%$ (calculated from Figure $8 \mathrm{a}$ ) when the cooling load varies from $30 \mathrm{~W} / \mathrm{m}^{2}$ to $70 \mathrm{~W} / \mathrm{m}^{2}$ (Figure 12). The maximal HRE difference of the same cooling load for the variable-air-volume system runs from $0.1 \%$ to $2.2 \%$ (calculated from Figure $8 \mathrm{~b}$ ) when the cooling load varies from $30 \mathrm{~W} / \mathrm{m}^{2}$ to $125 \mathrm{~W} / \mathrm{m}^{2}$ (Figure 12). The maximal HRE difference of the same cooling load for this stratum-ventilated classroom is smaller than that of the stratum-ventilated office. This is because the variation of the HRE for the stratum-ventilated classroom is smaller (Figures 8 and 10). The smaller maximal HRE difference of the same cooling load indicates the smaller energy efficiency improvement. Thus, the larger the variation of the HRE with the supply air temperature, supply airflow rate and cooling load, the more necessary the HRE model for the air-side modulation for energy saving and thermal comfort. Since the proposed HRE model based air-side modulation is convenient to employ in practice (Section 1), it is also recommended for the stratum-ventilated classroom for energy saving while 


\section{Applied Energy}

Volume 238, 15 March 2019, Pages 1237-1249

maintaining thermal comfort.

The HRE model based air-side modulation can be used for both design and operation phases. When designing the supply air temperature of the variable-air-volume system or the supply airflow rate of the constant-air-volume system, with the given cooling load (i.e., the designed cooling load) [65, 66], HREs with all possible combinations of the supply air temperatures (e.g., from $21^{\circ} \mathrm{C}$ to $25^{\circ} \mathrm{C}$ ) and supply airflow rates (e.g., from $7 \mathrm{ACH}$ to $15 \mathrm{ACH}$ ) are calculated using the HRE model (Equation 3) and compared when confining the room temperature within the desired range for thermal comfort (Equation 7). The room temperature can be obtained by solving Equations 1-3. By identifying the maximal HRE from all the calculated HREs, the supply air temperature or the supply airflow rate associated with the maximal HRE are determined as the designed supply air temperature of the variable-air-volume system or the designed supply airflow rate of the constant-air-volume system respectively. During the operation phase, the supply airflow rate, and supply and exit air temperatures are monitored by the building management system. With the monitored data, the room temperature is predicted by solving Equations 1-3. Then, PMV is calculated using the monitored supply airflow rate and predicted room temperature (Equation 7). If the calculated PMV indicates thermal comfort, the supply condition (i.e., the supply air temperature of the constant-air-volume system or the supply airflow rate of the variable-air-volume system) is kept invariable. Otherwise, the supply condition needs to be updated. When updating the supply condition, the cooling load is assumed to be the same as that before the updating (Equation 2) [67], and the HREs with all possible supply air temperatures or supply airflow rates are calculated. The supply air temperature or the supply airflow rate leading to the maximal HRE while maintaining thermal comfort is determined to be the updated supply condition for the constant-air-volume system or the variable-air-volume system respectively.

It is noted that since the HRE model is derived from the experiments under steady states. The air-side modulation of the design phase and the supervisory control in the operation is generally based on hourly data, where the steady-state assumption is acceptable $[38,68]$. The supervisory control has been widely implemented for the 


\section{Applied Energy}

Volume 238, 15 March 2019, Pages 1237-1249

operation optimization of the air conditioning system [68]. Thus, the HRE model based air-side modulation is applicable to both the design phase and the supervisory control of operation phase. The applicability of the HRE model based air-side modulation for dynamic processes needs to be further investigated. Section 4.2 confirms that the HRE model is also applicable to displacement ventilation, thus the proposed HRE model based air-side modulation is also promising for displacement ventilation. Since stratum ventilation and displacement ventilation can be used in offices, classrooms and retail shops and have the potential to be applied in telecommunication sites and data centers etc. [25, 69-73], this study contributes to the proper air-side modulation of these buildings for the maximal energy efficiency with the desired room temperature.

\section{Conclusions}

An HRE model is proposed as a function of the supply condition (i.e., supply air temperature and supply airflow rate) and cooling load. The HRE model determines its three constant coefficients by means of experiments/CFD simulations through multiple regression. The model can be extrapolated to wider ranges of the supply condition and cooling load than those used for the model determination. Six series of experiments (thirty-three cases) and CFD simulations (five cases) demonstrate that the proposed HRE model is accurate for stratum ventilation and displacement ventilation with different room geometries and air terminal configurations, with errors generally within $\pm 5 \%$ and mean absolute errors less than $4 \%$.

The applications of the HRE model to the air-side modulation for the two stratum-ventilated rooms have been investigated. The results show that the variable-air-volume system can serve a wider range of the cooling load than the constant-air-volume system. The conventionally used constant HRE is deficient in the room temperature prediction with an error up to $\pm 1.3^{\circ} \mathrm{C}$. The HRE model proposed for the air-side modulation of room temperature could improve thermal comfort. Moreover, the proposed HRE model based air-side modulation can improve the energy efficiency up to $67.3 \%$ while maintaining thermal comfort. 
Applied Energy

Volume 238, 15 March 2019, Pages 1237-1249

\section{Acknowledgment}

The work described in this paper is supported by a Research Grant from the Chengdu Research Institute of the City University of Hong Kong, Shuangliu, Chengdu, Sichuan, China (Project No. R-LAAD004) and National Natural Science Foundation of China (Grant No. 51608066).

\section{References}

[1] Zhang S, Sun Y, Cheng Y, Huang P, Oladokun MO, Lin Z. 2018. Response-surface-model-based system sizing for nearly/net zero energy buildings under uncertainty. Applied Energy, 228, 1020-1031.

[2] Huang P, Sun Y. 2019. A clustering based grouping method of nearly zero energy buildings for performance improvements. Applied Energy, 235, 43-55.

[3] Pérez-Lombard L, Ortiz J, Pout C. 2008. A review on buildings energy consumption information. Energy and buildings, 40(3), 394-398.

[4] Ai ZT, Mak CM, Cui DJ, Xue P. 2016. Ventilation of air-conditioned residential buildings: A case study in Hong Kong. Energy and Buildings, 127, 116-127.

[5] Deng Y, Feng Z, Fang J, Cao SJ. 2018. Impact of ventilation rates on indoor thermal comfort and energy efficiency of ground-source heat pump system. Sustainable Cities and Society, 37, 154-163.

[6] Wang W, Chen J, Huang G, Lu Y. 2017. Energy efficient HVAC control for an IPS-enabled large space in commercial buildings through dynamic spatial occupancy distribution. Applied Energy, 207, 305-323.

[7] Zhang S, Cheng Y. 2017. Performance improvement of an ejector cooling system with thermal pumping effect (ECSTPE) by doubling evacuation chambers in parallel. Applied Energy, 187, 675-688.

[8] Melikov AK. 2016. Advanced air distribution: Improving health and comfort while reducing energy use. Indoor Air, 26(1), 112-124.

[9] Cheng Y, Niu J, Gao N. 2012. Stratified air distribution systems in a large lecture theatre: A numerical method to optimize thermal comfort and maximize energy 
saving. Energy and Buildings, 55, 515-525.

[10]Cao G, Awbi H, Yao R, Fan Y, Sirén K, Kosonen R, Zhang JJ. 2014. A review of the performance of different ventilation and airflow distribution systems in buildings. Building and Environment, 73, 171-186.

[11]Zheng C, You S, Zhang H, Zheng W, Zheng X, Ye T, Liu Z. 2018. Comparison of air-conditioning systems with bottom-supply and side-supply modes in a typical office room. Applied Energy, 227, 304-311.

[12]Lin Z, Chow TT, Tsang CF, Fong KF, Chan LS. 2009. Stratum ventilation - a potential solution to elevated indoor temperatures. Building and Environment 44(11), 2256-2269.

[13]Cheng Y, Lin Z. 2015. Experimental investigation into the interaction between the human body and room airflow and its effect on thermal comfort under stratum ventilation. Indoor Air, 26(2), 274-85.

[14] Shao X, Wang K, Li X, Lin Z. 2018. Potential of stratum ventilation to satisfy differentiated comfort requirements in multi-occupied zones. Building and Environment, 143, 329-338.

[15]Cheng Y, Lin Z. 2015. Technical feasibility of a stratum-ventilated room for multiple rows of occupants. Building and Environment, 94, 580-592.

[16] Arens E, Zhang H, Huizenga C. 2006. Partial- and whole-body thermal sensation and comfort, Part II: Non-uniform environmental conditions. Journal of Thermal Biology, 31, 60-66.

[17]Nunneley SA, Reader DC, Maldonado RJ. 1982. Head-temperature effects on physiology, comfort, and performance during hyperthermia. Aviation Space and Environmental Medicine, 53(7), 623-628.

[18]Cheng Y, Fong ML, Yao T, Lin Z, Fong KF. 2014. Uniformity of stratum ventilated thermal environment and thermal sensation. Indoor Air, 24(5), $521-532$.

[19]Cheng Y, Lin Z, Fong AM. 2015. Effects of temperature and supply airflow rate on thermal comfort in a stratum-ventilated room. Building and Environment, 92, 


\section{Applied Energy}

Volume 238, 15 March 2019, Pages 1237-1249

269-277.

[20]Cheng Y, Lin Z. 2015. Experimental study of airflow characteristics of stratum ventilation in a multi-occupant room with comparison to mixing ventilation and displacement ventilation. Indoor Air, 25, 662-671.

[21]Huan C, Wang FH, Lin Z, Wu XZ, Ma ZJ, Wang ZH, Zhang LH. 2016. An experimental investigation into stratum ventilation for the cooling of an office with asymmetrically distributed heat gains. Building and Environment, 110, 76-88.

[22]Fong ML, Lin Z, Fong KF, Chow TT, Yao T. 2011. Evaluation of thermal comfort conditions in a classroom with three ventilation methods. Indoor Air, 21(3), 231-239.

[23]Lin Z, Wang J, Yao T, Chow TT. 2012. Investigation into anti-airborne infection performance of stratum ventilation. Building and Environment, 54, 29-38.

[24]Tian L, Lin Z, Wang Q. 2010. Comparison of gaseous contaminant diffusion under stratum ventilation and under displacement ventilation. Building and Environment, 45(9), 2035-2046.

[25]Lin Z, Lee CK, Fong S, Chow TT, Yao T, Chan ALS. 2011. Comparison of annual energy performances with different ventilation methods for cooling. Energy and Buildings, 43(1), 130-136.

[26]Huan C, Wang F, Wu X, Lin Z, Ma Z, Wang Z. 2018. Development of a nodal model for predicting the vertical temperature profile in a stratum-ventilated room. Energy and Buildings, 159, 99-108.

[27]Wu X, Olesen BW, Fang L, Zhao J. 2013. A nodal model to predict vertical temperature distribution in a room with floor heating and displacement ventilation. Building and Environment, 59, 626-634.

[28]Buratti C, Palladino D, Ricciardi P. 2016. Application of a new 13-value thermal comfort scale to moderate environments. Applied Energy, 180, 859-866.

[29] Mei J, Xia X, Song M. 2018. An autonomous hierarchical control for improving indoor comfort and energy efficiency of a direct expansion air conditioning 


\section{Applied Energy}

Volume 238, 15 March 2019, Pages 1237-1249

system. Applied Energy, 221, 450-463.

[30]Wang H, Zhou P, Guo C, Tang X, Xue Y, Huang C. 2019. On the calculation of heat migration in thermally stratified environment of large space building with sidewall nozzle air-supply. Building and Environment, 147, 221-230.

[31]Chen YL, Wen J. 2012. The selection of the most appropriate airflow model for designing indoor air sensor systems. Building and Environment, 50, 34-43.

[32]Fontanini AD, Vaidya U, Ganapathysubramanian B. 2016. A methodology for optimal placement of sensors in enclosed environments: A dynamical systems approach. Building and Environment, 100, 145-161.

[33]Etheridge DW, Sandberg M. 1996. Building ventilation: theory and measurement (Vol. 50). Chichester: John Wiley \& Sons.

[34]Krajčík M, Simone A, Olesen BW. 2012. Air distribution and ventilation effectiveness in an occupied room heated by warm air. Energy and Buildings, 55, 94-101.

[35]Lee CK, Fong KF, Lin Z, Chow TT. 2013. Year-round energy saving potential of stratum ventilated classrooms with temperature and humidity control. HVAC\&R Research, 19(8), 986-991.

[36]Fong KF, Lee CK, Lin, Z. 2019. Investigation on effect of indoor air distribution strategy on solar air-conditioning systems. Renewable Energy, 131, 413-421.

[37]Zhang S, Cheng Y, Fang Z, Huan C, Lin Z. 2017. Optimization of room air temperature in stratum-ventilated rooms for both thermal comfort and energy saving. Applied Energy, 204, 420-431.

[38]Zhang S, Huang P, Sun Y. 2016. A multi-criterion renewable energy system design optimization for net zero energy buildings under uncertainties. Energy, 94, 654-665.

[39]Nielsen PV. 1992. Air distribution systems: room air movement and ventilation effectiveness. Dept. of Building Technology and Structural Engineering.

[40]Xing H, Awbi HB. 2002. Measurement and calculation of the neutral height in a room with displacement ventilation. Building and Environment, 37(10), 961-967. 
Applied Energy

Volume 238, 15 March 2019, Pages 1237-1249

[41]Chen H, Janbakhsh S, Larsson U, Moshfegh B. 2015. Numerical investigation of ventilation performance of different air supply devices in an office environment. Building and Environment, 90, 37-50.

[42]Mao N, Song M, Deng S. 2016. Application of TOPSIS method in evaluating the effects of supply vane angle of a task/ambient air conditioning system on energy utilization and thermal comfort. Applied Energy, 180, 536-545.

[43]Rohdin P, Moshfegh B. 2007. Numerical predictions of indoor climate in large industrial premises. A comparison between different $\mathrm{k}-\varepsilon$ models supported by field measurements. Building and Environment, 42(11), 3872-3882.

[44]Chen Q, Van Der Kooi J, Meyers A. 1988. Measurements and computations of ventilation efficiency and temperature efficiency in a ventilated room. Energy and Buildings, 12(2), 85-99.

[45]ASHRAE. 2017. Thermal environmental conditions for human occupancy, ASHRAE Standard 55-2017. American Society of Heating, Refrigerating and Air-conditioning Engineers, Atlanta, Georgia.

[46]Hwang RL, Cheng MJ, Lin TP, Ho MC. 2009. Thermal perceptions, general adaptation methods and occupant's idea about the trade-off between thermal comfort and energy saving in hot-humid regions. Building and Environment, 44(6), 1128-1134.

[47]Carlucci S, Bai L, de Dear R, Yang L. 2018. Review of adaptive thermal comfort models in built environmental regulatory documents. Building and Environment, $137,73-89$.

[48]Karimipanah T, Awbi HB. 2002. Theoretical and experimental investigation of impinging jet ventilation and comparison with wall displacement ventilation. Building and Environment, 37(12), 1329-1342.

[49]Liu C, Li A, Yang C, Zhang W. 2017. Simulating air distribution and occupants' thermal comfort of three ventilation schemes for subway platform. Building and Environment, 125, 15-25.

[50]Chenvidyakarn T, Woods AW. 2008. On underfloor air-conditioning of a room containing a distributed heat source and a localised heat source. Energy and 
Applied Energy

Volume 238, 15 March 2019, Pages 1237-1249

Buildings, 40(7), 1220-1227.

[51]Fang Z, Zhang S, Cheng Y, Fong AM, Oladokun MO, Lin Z, Wu H. 2018. Field study on adaptive thermal comfort in typical air conditioned classrooms. Building and Environment, 133, 73-82.

[52]Ren Z, Chen D. 2018. Modelling study of the impact of thermal comfort criteria on housing energy use in Australia. Applied Energy, 210, 152-166.

[53] Schiavon S, Webster T, Dickerhoff D, Bauman F. 2014. Stratification prediction model for perimeter zone UFAD diffusers based on laboratory testing with solar simulator. Energy and Buildings, 82, 786-794.

[54]Mao N, Pan D, Li Z, Xu Y, Song M, Deng S. 2017. A numerical study on influences of building envelope heat gain on operating performances of a bed-based task/ambient air conditioning (TAC) system in energy saving and thermal comfort. Applied Energy, 192, 213-221.

[55]Olesen BW, Simone A, Krajclik M, Causone F, Carli MD. 2011. Experimental study of air distribution and ventilation effectiveness in a room with a combination of different mechanical ventilation and heating/cooling systems. International Journal of Ventilation, 9(4), 371-383.

[56]Zukowska D, Melikov A, Popiolek Z. 2007. Thermal plume above a simulated sitting person with different complexity of body geometry. Proceedings of the 10th International Conference on Air Distribution in Rooms-Roomvent 2007, Helsinki, Finland, 3, 191-198.

[57]Willmott CJ, Matsuura K. 2005. Advantages of the mean absolute error (MAE) over the root mean square error (RMSE) in assessing average model performance. Climate Research, 30(1), 79-82.

[58]Lin Z, Chow TT, Tsang CF, Fong KF, Chan LS. 2005. CFD study on effect of the air supply location on the performance of the displacement ventilation system. Building and Environment, 40(8), 1051-1067.

[59]Lee CK, Lam HN. 2007. Computer modeling of displacement ventilation systems based on plume rise in stratified environment. Energy and Buildings, 39(4), 427-436. 
Applied Energy

Volume 238, 15 March 2019, Pages 1237-1249

[60]Cui X, Mohan B, Islam MR, Chou SK, Chua KJ. 2017. Energy performance evaluation and application of an air treatment system for conditioning building spaces in tropics. Applied Energy, 204, 1500-1512.

[61] Yao T, Lin Z. 2014. An experimental and numerical study on the effect of air terminal layout on the performance of stratum ventilation. Building and Environment, 82, 75-86.

[62]Chow TT, Fong KF, Givoni B, Lin Z, Chan ALS. 2010. Thermal sensation of Hong Kong people with increased air speed, temperature and humidity in air-conditioned environment. Building and Environment, 45(10), 2177-2183.

[63]Alfano FRDA, Palella BI, Riccio G. 2011. The role of measurement accuracy on the thermal environment assessment by means of PMV index. Building and Environment, 46(7), 1361-1369.

[64]Hasan MH, Alsaleem F, Rafaie M. 2016. Sensitivity study for the PMV thermal comfort model and the use of wearable devices biometric data for metabolic rate estimation. Building and Environment, 110, 173-183.

[65]Cheng Y, Yang B, Lin Z, Yang J, Du Z. 2018. Cooling load calculation methods in spaces with stratified air: A brief review and numerical investigation. Energy and Buildings, 165, 47-55.

[66]Liang C, Shao X, Melikov AK, Li X. 2018. Cooling load for the design of air terminals in a general non-uniform indoor environment oriented to local requirements. Energy and Buildings, 174, 603-618.

[67]Gao J, Xu X, Li X, Zhang J, Zhang Y, Wei G. 2018. Model-based space temperature cascade control for constant air volume air-conditioning system. Building and Environment, 145: 308-318.

[68] Wang S, Ma Z. 2008. Supervisory and optimal control of building HVAC systems: A review. HVAC\&R Research, 14(1), 3-32.

[69]Wu G, Zeng F, Zhu G. 2017. Research on ventilation cooling system of communication base stations for energy saving and emission reduction. Energy and Buildings, 147, 67-76. 
Applied Energy

Volume 238, 15 March 2019, Pages 1237-1249

[70]Zhang K, Zhang Y, Liu J, Niu X. 2018. Recent advancements on thermal management and evaluation for data centers. Applied Thermal Engineering,142, 215-231.

[71] Garimella SV, Persoons T, Weibel J, Yeh LT. 2013. Technological drivers in data centers and telecom systems: Multiscale thermal, electrical, and energy management. Applied Energy, 107, 66-80.

[72] Sorrentino M, Acconcia M, Panagrosso D, Trifirò A. 2016. Model-based energy monitoring and diagnosis of telecommunication cooling systems. Energy, 116, 761-772.

[73] Spagnuolo A, Petraglia A, Vetromile C, Formosi R, Lubritto C. 2015. Monitoring and optimization of energy consumption of base transceiver stations. Energy, 81, 286-293. 